\title{
The human microglial HMC3 cell line: where do we stand? A systematic literature review
}

\author{
Cinzia Dello Russo ${ }^{1,2^{*}}$ D, Natalia Cappoli ${ }^{1}$, Isabella Coletta ${ }^{3}$, Daniele Mezzogori ${ }^{4}$, Fabiola Paciello ${ }^{5}$, \\ Giacomo Pozzoli ${ }^{1,2}$, Pierluigi Navarra ${ }^{1,2}$ and Alessandra Battaglia ${ }^{6}$
}

\begin{abstract}
Microglia, unique myeloid cells residing in the brain parenchyma, represent the first line of immune defense within the central nervous system. In addition to their immune functions, microglial cells play an important role in other cerebral processes, including the regulation of synaptic architecture and neurogenesis. Chronic microglial activation is regarded as detrimental, and it is considered a pathogenic mechanism common to several neurological disorders. Microglial activation and function have been extensively studied in rodent experimental models, whereas the characterization of human cells has been limited due to the restricted availability of primary sources of human microglia. To overcome this problem, human immortalized microglial cell lines have been developed. The human microglial clone 3 cell line, HMC3, was established in 1995, through SV40-dependent immortalization of human embryonic microglial cells. It has been recently authenticated by the American Type Culture Collection (ATCC ${ }^{\oplus}$ ) and distributed under the name of HMC3 (ATCC ${ }^{\circledR}$ CRL-3304). The HMC3 cells have been used in six research studies, two of which also indicated by ATCC $^{\circledR}$ as reference articles. However, a more accurate literature revision suggests that clone 3 was initially distributed under the name of CHME3. In this regard, several studies have been published, thus contributing to a more extensive characterization of this cell line. Remarkably, the same cell line has been used in different laboratories with other denominations, i.e., CHME-5 cells and C13-NJ cells. In view of the fact that "being now authenticated by ATCC ${ }^{\otimes \prime}$ may imply a wider distribution of the cells, we aimed at reviewing data obtained with the human microglia cell line clone 3, making the readers aware of this complicated nomenclature. In addition, we also included original data, generated in our laboratory with the HMC3 (ATCC ${ }^{\circledR}$ CRL-3304) cells, providing information on the current state of the culture together with supplementary details on the culturing procedures to obtain and maintain viable cells.
\end{abstract}

Keywords: Human microglial cell line, HMC3, HMC-3, CHME3, CHME-3, CHME-5, C13-NJ, Molecular phenotype, Molecular signature, Functional properties, IL-6, Chemokines, Free oxygen radicals

\section{Background}

Microglial cells are unique myeloid cells residing in the parenchyma of the healthy central nervous system (CNS). These cells arise from erythro-myeloid precursors in the yolk sac and enter the brain early during development. Although sharing a common lineage with

\footnotetext{
* Correspondence: cinzia.dellorusso@unicatt.it

${ }^{1}$ Institute of Pharmacology, Università Cattolica del S. Cuore, L.go F Vito 1, 00168 Rome, Italy

${ }^{2}$ Pharmacology Unit, Fondazione Policlinico Universitario A. Gemelli IRCCS, Rome, Italy

Full list of author information is available at the end of the article
}

monocyte-derived macrophages, microglia retain unique molecular signatures $[1,2]$ and acquire specific functional properties which make them substantially different from other populations of myeloid cells present in the brain (i.e., perivascular macrophages, meningeal macrophages, and choroid plexus macrophages) [3]. As the resident immune cells of the brain parenchyma, microglia are constantly monitoring the CNS microenvironment, being able to detect extracellular changes and become rapidly activated in response to different noxious stimuli (effector function). This activity is important in the regulation of brain homeostasis during

(C) The Author(s). 2018 Open Access This article is distributed under the terms of the Creative Commons Attribution 4.0 International License (http://creativecommons.org/licenses/by/4.0/), which permits unrestricted use, distribution, and 
development and in the adult brain, both in physiological conditions as well as pathology [4]. In addition to their immune functions, microglial cells seem to exert an important role in other cerebral processes, including the regulation of synaptic architecture [5-8] and neurogenesis [9-11], to name a few. Microglia can indeed produce several mediators, among which cytokines (with both pro- and anti-inflammatory activities) and chemokines, but also growth factors and neurotrophins. In addition, they can perform phagocytosis and produce reactive oxygen and nitrogen species, including nitric oxide (NO) mainly produced by the upregulation of the inducible form of NO synthase (iNOS, also known as NOS2). Chronic microglial activation seems to be a common pathogenic mechanism underlying several neurological disorders [12, 13]; therefore, studies on the regulatory mechanisms of microglial activation are important for a large spectrum of cerebral diseases. Accordingly, numerous experimental models have been established to address the issue.

In vitro, microglial functions have been extensively characterized using rodent cultures of microglial cells, either rat primary cultures derived from brain cortices of 1- to 2-day-old newborn animals [14] or immortalized murine cell lines [15]. However, rodent microglia display important biochemical and pharmacological differences compared to human microglia [16]. On the other hand, microglia research using human cells has been limited due to the restricted availability of primary sources of human microglia, including aborted fetal tissue, biopsies from epileptic patients, normal tissue from brain tumor excisions, or postmortem brain tissue. In this respect, human microglial cell lines allow to overcome this problem and can be considered a valuable experimental model. Several cell lines have been generated in different laboratories [17, 18], including more recent lines derived from adult brain tissue [19]. All these cell lines were developed through SV40 immortalization of human primary microglial cells, whereas a fraction of SV40-immortalized adult microglial cells were further engineered to express the human telomerase reverse transcriptase (hTERT) and reduce the proliferation rate [19]. To the best of our knowledge, two cell lines are commercially available, the human microglial clone 3 cell line, HMC3 [17, 20-22] and the "Immortalized Human Microglia - SV40", developed and distributed by Applied Biological Materials (Vancouver, Canada) [23-28]. The HMC3 has been recently authenticated by the American Type Culture Collection $\left(\mathrm{ATCC}^{\circ}\right)$, a leading nonprofit organization in the authentication and distribution of biologic material, microorganisms, and standards. The cell line is distributed by ATCC ${ }^{\circ}$ under the catalog designation of HMC3 (ATCC ${ }^{\circ} \mathrm{CRL}-3304$ ). Interestingly, a PubMed search (database accessed on June 4, 2018), using (HMC3) OR (HMC-3) as keywords retrieved 24 papers, among which only seven are indeed articles related to the human microglial HMC3 cell line, i.e., six original studies $[20,21,29-32]$ and one review article [22]. Two of these original papers are also included in the reference list reported in the $\mathrm{HMC} 3$ (ATCC ${ }^{\circ} \mathrm{CRL}-3304$ ) cell line's data sheet $[20,21]$. However, a more accurate literature revision would suggest that clone 3 circulated among different laboratories also under the name of CHME3 microglial cells. In fact, a PubMed search including (CHME3) OR (CHME-3) as keywords allowed us to identify 21 additional articles, published between 1999 and 2018. All these studies employed the CHME3 cell line, thus contributing to a more extensive characterization of the human microglial clone 3. In Fig. 1, it is reported a historical reconstruction of the distribution process of this cell line across different laboratories, based on published articles. Remarkably, the same cell line has been used in several laboratories with other denominations, i.e., C13-NJ cells and CHME-5 cells. Since "being now authenticated by ATCC" may imply a wider distribution of the cells, we aimed at reviewing data obtained with the human microglia cell line clone 3, making the readers aware of this complicated denomination. In addition, we also included original data, generated in our laboratory with the HMC3 (ATCC CRL-3304) cell line, providing information on the current state of the culture together with additional details on the culturing procedures to obtain and maintain viable cells. We believe that a systematic revision of this literature can be regarded as an important starting point for researchers planning to use this cell line in their experimental paradigms.

\section{The human microglial HMC3 cell line}

The human microglial clone 3 cell line, HMC3 [20], was established in the laboratory of Prof. Tardieu in 1995, through SV40-dependent immortalization of human microglial cells [17]. The detailed methodology for the preparation of primary cultures of human microglial cells was previously published [33]. Briefly, microglial cells were isolated by circular shaking from primary mixed cultures of human spinal cord and cortical cells, derived from 8-to 12-week-old embryos and kept in vitro for 10-15 days. Microglial cells were described as slowly diving cells, able to reach confluency in 8-12 days after seeding. The cells showed a complex morphology, with different shapes, a vacuolated cytoplasm, and short processes. In addition, microglial cells were stained positive for several myeloid specific markers, including cluster of differentiation (CD)68, CD11b, and CD14. Interestingly, for the detection of CD68, different antibodies were used, i.e., clones Ki-M7 and Ki-M6 from Behring (Rueil-Malmaison, France) and clone EBM/11 from Dako Corporation (Santa Barbara, CA). More importantly, quantification of CD68 expression varied with the primary antibody used. At in vitro day 1 , 


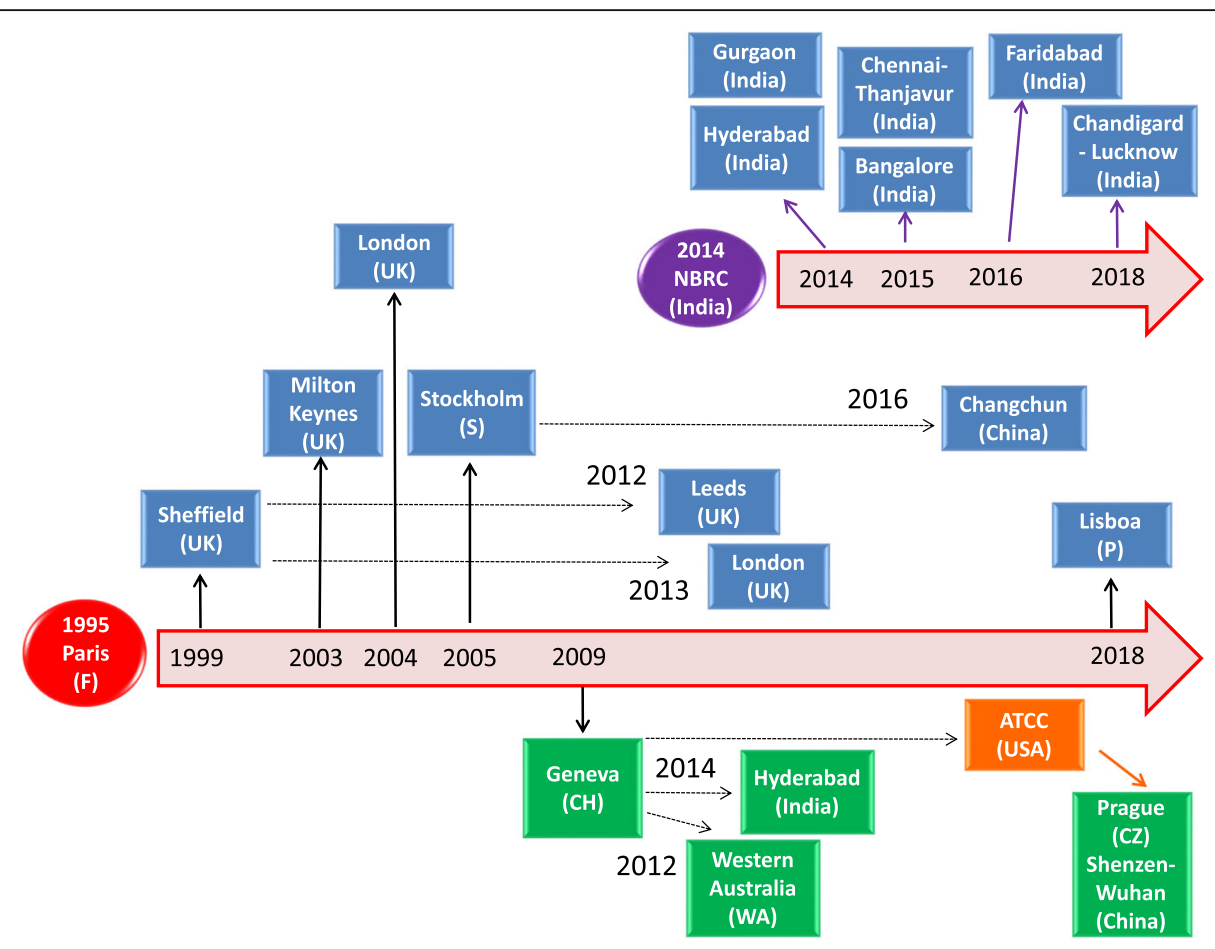

Fig. 1 Historical reconstruction of the distribution process of the human microglial clone 3 cell line. The human microglial clone 3 cell line was developed in the laboratory of Prof. M Tardieu, Paris, in 1995 (red circle). As shown in the picture, clone 3 has been distributed worldwide, with the acronym of CHME3 cells (blue boxes) or HMC3 cells (green boxes). Distribution followed two main pathways, either directly from Prof. Tardieu's laboratory (black thick arrows) or indirectly by the first recipient laboratory (black dotted arrows). A second main distributor of the CHME3 cell line is the laboratory of Prof. A Basu, National Brain Research Centre (NBRC), India (purple circle). Since 2014, this laboratory appears to be the main distributor of the CHME3 cells in India. However, we could not trace on the timeline when the cell line was transferred from the laboratory of Prof. Tardieu to NBRC. In addition, we identified several studies (not reported in the schematic), in which the CHME3 cells were used without any indication of the source, and one study in which the cell line was provided by an Academic institution without any link to published data. In 2016, the HMC3 cells were transferred to ATCC ${ }^{\oplus}$, USA (orange box) and authenticated and distributed under the catalog designation of HMC3 (ATCC ${ }^{\oplus}$ CRL-3304)

$83.3 \pm 2.9( \pm \mathrm{SD}) \%$ were detected as CD68 Ki-M7-positive cells, whereas only $33.5 \pm 12 \%$ were CD68 EBM/11 positive and $18 \pm 2.8 \%$ CD68 Ki-M6 positive. In addition, primary human microglial cells tended to lose the positivity for CD68 Ki-M6 and EBM/11 during in vitro culturing. Similarly, the expression of CD14 $(34 \pm 12 \%$ of positive cells at in vitro day 1) disappeared after 10 days in culture ( $<1 \%$ positive cells). Microglial cells were virtually negative for class II major histocompatibility complex (MHCII, $4 \pm 4 \%$ of positive cells at in vitro day $1,<1 \%$ after 10 days in culture) and CD4 antigen expression. Conversely, most of the cells steadily displayed nonspecific esterase activity (NSE, 90\% positive cells at day 1 vs $81 \pm 1 \%$ at day 10) and were able to phagocytize zymosan particles $(97 \%$ at day 1 vs $81 \pm 1 \%$ at day 10 ) [33].

Immortalized microglial cells were generated by transfection of the SV40 T antigen in primary human microglial cultures, derived from 8- to 10-week old embryos. Several clones of immortalized cells were isolated, albeit clonality could not be totally confirmed due to inability of the cells to grow at very low density [17]. It should also be pointed out that primary CNS cultures are not necessarily restricted to parenchymal microglia, and other myeloid populations may be present in these cultures, possibly contributing to the culture heterogeneity. Immortalized cells acquired rapid growth capacity (with doubling times ranging between 24 and $48 \mathrm{~h}$ ) and retained most of the phenotypical and morphological properties of the primary microglial cell source, except for a higher percentage of CD68 EBM/11-positive cells and lower phagocytic activity. Antigenic expression was confirmed to be stable for 35 passages in vitro (data not shown). As summarized in Table 1, the human microglial clone 3 (HMC3 cells) was originally characterized as NSE, CD68, and CD11b positive (80-90\%), and CD14, MHCII, CD4 negative under basal conditions [17]. However, the expression level of MHCII increased in response to treatment with human recombinant interferon- $\gamma$ (IFN $\gamma, 100 \mathrm{U} / \mathrm{ml}$ for $18 \mathrm{~h}$; BoeringherMannheim, Mayland France) (Table 1). The percentage of MHCII-positive cells $(43 \pm 10 \%, \pm$ SD) was higher in HMC3 cells in comparison to other clones $(4-13 \%$ in 
Table 1 Antigenic profile of the human microglial clone 3 cell line

\begin{tabular}{|c|c|c|c|c|c|c|c|}
\hline \multirow[t]{2}{*}{ Markers } & \multicolumn{2}{|c|}{ Original characterization } & \multicolumn{2}{|l|}{ CHME3 cells } & \multicolumn{2}{|c|}{ HMC3 cells } & \multirow[t]{2}{*}{ References } \\
\hline & Resting & Stimulated & Resting & Stimulated & Resting & Stimulated & \\
\hline \multicolumn{8}{|l|}{ Myeloid Markers } \\
\hline CD68 Ki-M7 & +++ & & & & & & [17] \\
\hline CD68 Ki-M6 & - & & & & & & [17] \\
\hline CD68 EBM/11 & ++ & & + & & & & {$[17,35]$} \\
\hline CD68 & & & +++ & & $-/++$ & IFNY: $\uparrow$ & {$[20,29,38]$} \\
\hline$C D 11 b$ & +++ & & $\begin{array}{l}+ \text { (and also at } \\
\text { mRNA level) }\end{array}$ & $A \beta_{1-42}: \uparrow$ & - & IFNY: $\uparrow$ & {$[17,20,29,39,40]$} \\
\hline CD45 & & & & & + & & [29] \\
\hline $\mid \mathrm{BA} 1$ & & & & & + & & {$[20,29]$} \\
\hline $\mathrm{MHCll}$ & - & IFNY: $\uparrow$ & + & & $-/+$ & IFNY: $\uparrow$ & {$[17,20,29,37,39]$} \\
\hline CD14 & - & & & & + & & {$[17,20,29]$} \\
\hline MCSF-R & & & $\begin{array}{l}\text { + (western } \\
\text { immunoblot) }\end{array}$ & & & & [41] \\
\hline TLR1 & & & + & & & & [40] \\
\hline TLR 2 and 6 & & & $+++/++$ & $\begin{array}{l}\text { HCV NS3 } \\
\text { protein: } \uparrow\end{array}$ & & & [40] \\
\hline \multicolumn{8}{|c|}{ Polarization markers } \\
\hline CD40 & & & $+/++$ & $A \beta_{1-42}: \downarrow / \uparrow$ & & & {$[37,39,43]$} \\
\hline CD80 & & & + & & & & [37] \\
\hline CD86 & & & + & $\begin{array}{l}A \beta_{1-42:}: \\
\text { no effect }\end{array}$ & & & {$[37,39,43]$} \\
\hline CD163 & & & + & $\begin{array}{l}A \beta_{1-42:}: \\
\text { no effect }\end{array}$ & & & {$[37,43]$} \\
\hline CD206 & & & + & $\begin{array}{l}A \beta_{1-42:} \\
\text { no effect }\end{array}$ & & & {$[37,43]$} \\
\hline \multicolumn{8}{|c|}{ Chemokine receptors } \\
\hline CCR1 & & & & & + & & [29] \\
\hline CCR2 & & & - & & + & & {$[29,38]$} \\
\hline CCR3 & & & $++(\mathrm{MFI})$ & $\begin{array}{l}\text { TNFa: } \uparrow \\
\text { IFNY: } \uparrow\end{array}$ & & & [38] \\
\hline CCR4 & & & & & ++ & & [29] \\
\hline CCR5 & & & + & & +++ & & {$[29,38]$} \\
\hline CCR10 & & & + (mRNA level) & $\begin{array}{l}\text { TNFa: } \uparrow \\
\text { (mRNA level) }\end{array}$ & & & [38] \\
\hline CXCR1 & & & $++(\mathrm{MFI})$ & & ++ & & {$[29,38]$} \\
\hline CXCR3 & & & $+++(M F I)$ & $\begin{array}{l}\text { TNFa: slight } \uparrow \\
\text { IFNY: slight } \uparrow\end{array}$ & +++ & & {$[29,38]$} \\
\hline CX3CR1 & & & & & +++ & & [29] \\
\hline \multicolumn{8}{|l|}{ Other markers } \\
\hline CD4 & - & & & & & & [17] \\
\hline NSE & +++ & & & & & & [17] \\
\hline GFAP & - & & $\begin{array}{l}\text { - (including at } \\
\text { mRNA level) }\end{array}$ & & - & & {$[17,20,35,40]$} \\
\hline NF70KD & - & & & & & & [17] \\
\hline$A 7 n A c R$ & & & + & & & & [44] \\
\hline
\end{tabular}

Resting conditions:,$+ 1-33 \%$ of the cell population (or a positive immunocytochemistry);,$++ 34-66 \% ;+++,>66 \% ;-,<1 \%$. Inflammatory stimuli: $\uparrow$, upregulation; $\downarrow$, downregulation. MFI, mean fluorescence intensity 
clones 1,2, and 4) and closer to what observed in primary cultures $(50 \%)$ after stimulation with IFN $\gamma$. All the immortalized cells were negative for the specific astrocyte marker, glial fibrillary acidic protein (GFAP), and for the neuronal neurofilament staining (NF70KD) (Table 1). At a functional level, immortalized cells produced and released sizable amounts of interleukin (IL)- 6 under basal conditions (Table 2). Interestingly, the HMC3 cells secreted higher amounts in comparison to the other clones [17]. Unfortunately, a direct comparison with primary microglial

Table 2 Production of cytokines, chemokines, and other inflammatory mediators

\begin{tabular}{|c|c|c|c|c|c|c|c|}
\hline \multirow[t]{2}{*}{ Markers } & \multicolumn{2}{|c|}{ Original characterization } & \multicolumn{2}{|l|}{ CHME3 cells } & \multicolumn{2}{|l|}{ HMC3 cells } & \multirow[t]{2}{*}{ References } \\
\hline & Resting & Stimulated & Resting & Stimulated & Resting & Stimulated & \\
\hline \multicolumn{8}{|c|}{ Pro-inflammatory molecules } \\
\hline IL-6 & $1553 \pm 142$ & $\begin{array}{l}\text { IL-1a: > } 2500 \\
\text { LPS: } 2110 \pm 111\end{array}$ & $\begin{array}{l}\text { 20-950/sizable } \\
\text { amount }\end{array}$ & $\begin{array}{l}\text { LPS: } 2-4 \text { fold } \uparrow \\
\text { IL-1 } 13: 50 \text { fold } \uparrow \\
\text { IFNY: modest } \uparrow \\
\text { IL-1 } 1 \beta+\text { IFNY: } \\
\text { additional } \uparrow \\
\text { A } \beta_{1-40}: 2-12 \text { fold } \uparrow \\
\text { A } \beta_{1-40}+\text { IFNY: } \\
\text { no- additional } \uparrow \\
\text { A } \beta_{1-42}: \text { no effect } \\
\text { a-MSH: } \uparrow \\
\text { EPA: } \uparrow \\
\text { HCV NS3: } \uparrow\end{array}$ & $\begin{array}{l}\text { Sizable amount / } \\
\text { (mRNA level) }\end{array}$ & $\begin{array}{l}\text { HIV-vector: } \uparrow \\
\text { HIV-U937: } \uparrow\end{array}$ & $\begin{array}{l}{[17,20,21,30,36,} \\
37,40,43,47,48]\end{array}$ \\
\hline TNFa & ND & ND & $4-8 / N D$ & $\begin{array}{l}A \beta_{1-40}: \text { no effect } \\
A \beta_{1-42}: \text { modest } \uparrow \\
\text { HCV NS3: } \uparrow\end{array}$ & (mRNA level) & & $\begin{array}{l}{[17,21,37,40,43,} \\
44,47]\end{array}$ \\
\hline IL-1a & & & ND & $A \beta_{1-40}:$ no effect & & & [47] \\
\hline $\mathbb{I L}-1 \beta$ & & & ND & $\begin{array}{l}A \beta_{1-40}: \text { no effect } \\
\text { HCV NS3: } \uparrow\end{array}$ & ND /(mRNA level) & & {$[21,30,40,47]$} \\
\hline Caspase-1 & & & ND & $A \beta_{1-40}:$ no effect & & & [47] \\
\hline $\mid \mathrm{L}-12$ & & & & LPS: $\uparrow$ & & & {$[52]$} \\
\hline $\mathrm{IFNY}$ & & & & LPS: $\uparrow$ & ND & & {$[30,52]$} \\
\hline iNOS & & & $\begin{array}{l}16 \% \text { of cells } \\
\text { (positive } \\
\text { immunoreactivity) }\end{array}$ & & (mRNA level) & & {$[20,36]$} \\
\hline ROS & & & & & Sizable amount & $\begin{array}{l}\text { HIV TAT-C } \\
\text { protein: } \\
\text { modest } \uparrow\end{array}$ & {$[20,21]$} \\
\hline \multicolumn{8}{|c|}{ Antinflammatory molecules } \\
\hline $\mid \mathrm{LL}-4$ & & & & & ND & & {$[30]$} \\
\hline IL-10 & & & 5,4 & $A \beta_{1-42}:$ no effect & ND & & {$[30,43]$} \\
\hline TGFß1 & & & $\sim 8$ & & (mRNA level) & & {$[20,37]$} \\
\hline TGF $\beta 2$ & & & $\sim 100$ & & & & {$[37]$} \\
\hline \multicolumn{8}{|l|}{ Chemokines } \\
\hline $\mathrm{CCL} 2$ & & & & & & HIV-U937: $\uparrow$ & {$[30]$} \\
\hline $\mathrm{CCL} 5$ & & & & & Sizable amount & $\begin{array}{l}\text { HIV-vector: } \uparrow \\
\text { HIV-U937: } \uparrow\end{array}$ & {$[30]$} \\
\hline $\mid \mathrm{L}-8$ & & & & HCV NS3: $\uparrow$ & & & {$[40]$} \\
\hline CXCL10 & & & & & & $\begin{array}{l}\text { HIV-vector: } \uparrow \\
\text { HIV-U937: } \uparrow\end{array}$ & {$[30]$} \\
\hline
\end{tabular}
at the mRNA levels, in the CHME3 cells when co-cultured with differentiated neuronal SH-SY5Y wild type cells for $24,48,72 \mathrm{~h}$. These markers were significantly upregulated in presence of the $\mathrm{SH}_{\text {swe }}$ differentiated neuronal cells, with major modifications observed for IL-1 3 and IL-6 gene expression at $72 \mathrm{~h}$ [50]. In addition, the mRNA levels of both pro-inflammatory (IL-1 $\beta$, IL-6, and TNFa) and anti-inflammatory (IFN $\beta$, IL-4, and IL-10) cytokines increased in response to CHME3 cell infection with the Japanese Encephalitis Virus (JEV) $[53,54]$ 
cells was not included in the paper, and it is difficult to extrapolate from a previous study [34], in which a biological assay was employed to measure the cytokine's production in place of the enzyme-linked immunosorbent assay (ELISA) adopted later. However, in all the immortalized microglial clones, including the HMC3 cells, basal production of IL-6 was consistently increased by $24-\mathrm{h}$ treatments with human recombinant IL-1 $\alpha(10 \mathrm{U} / \mathrm{ml}$, Boeringher-Mannheim) or by lipopolysaccharide (LPS) from Salmonella typhimurium (Sigma; $10 \mu \mathrm{g} / \mathrm{ml}$ ) (Table 2). Again, a direct comparison with primary microglial cultures appears difficult due to substantial differences in the amount of IL- $1 \alpha /$ LPS used for the stimulation and the assay employed to assess IL-6 production. However, it seems that the immortalized cell lines were less responsive to LPS in comparison to primary cultures [17, 34]. Similarly to primary cells, all the immortalized microglial cell clones were unable to produce tumor necrosis $\alpha$ (TNF $\alpha$, data not shown), neither spontaneously nor after pro-inflammatory activation [17]. The production of TNFa was evaluated with a biological assay. Interestingly, lack of TNFo production and CD14 expression was considered a specific property of human embryonic microglia.

\section{Cell morphology}

A description of the morphology of the immortalized microglial cells was initially reported by Janabi and colleagues [17]. The authors did not distinguish among different clones, and in general they described the immortalized cells as "globular or elongated with thick processes and numerous dark granulation in a large and clear cytoplasm", page 106. Cells were originally maintained in Eagle's minimum essential medium (EMEM), containing $6 \mathrm{~g} / \mathrm{l}$ glucose, $10 \%$ fetal calf serum (FCS), $2 \mathrm{mM}$ glutamine, and antibiotics. When cultured on fibronectin-coated coverslips, the human microglial CHME3 cells showed mostly a globular morphology, detected by rhodamine-phalloidin staining, with a more intense signal surrounding the nucleus [35]. Interestingly, changes in the actin polymerization were induced by short term exposure (60 $\mathrm{min}$ ) to human chemokines (MCP-1 or RANTES, $20 \mathrm{ng} / \mathrm{ml}$ ), thus suggesting the ability of human microglia to migrate in response to chemotactic gradients. In contrast to the CHME3 cells, rat microglia displayed a more complex and branched morphology in response to rat chemokines, with an intense rhodamine-phalloidin staining in pseudopodialike structures. However, both human and rodent microglia were able to migrate in response to several human chemokines showing a similar pattern, albeit the CHME3 cells responded to lower concentrations and in shorter times [35]. The CHME3 cells have been mostly maintained in Dulbecco's modified MEM (DMEM), retaining their morphological features (i.e., globular cells with dark cytoplasmic vacuoles) [36, 37]. On the other hand, a phase-contrast image of the HMC3 cells, published later by Etemad and colleagues [29], showed the presence of different morphological phenotypes in the same culture, including globular, bipolar, and very elongated cells. Noteworthy, these cells were maintained in a more enriched medium (i.e., DMEM-F12) containing also a higher percentage of FCS (15\% FCS).

\section{Antigenic profile}

The antigenic profile of the human microglial clone 3 cells, as it emerges from published studies, is outlined in Table 1. In line with the original characterization [17], it was later confirmed that the CHME3 cell line were CD68 EBM/11 positive and GFAP negative [35]. Consistently, the expression of CD68 was detected in resting CHME3 cells using a different primary antibody (DAKO, UK) [38]. In addition, a small percentage (around 5\%) of CHME3 cells was found to express the MCHII antigen under basal conditions [37], and resting CHME3 cells were described as MHCII and CD11b positive by flow-cytometry [39]. Expression of CD11b and lack of GFAP was further confirmed at transcriptional level [40]. In addition, it was shown that resting CHME3 cells expressed different toll-like receptors (TLRs), including TLR1, TLR2, and TLR 6; and that exposure to the HCV NS3 viral protein significantly increased the expression level of TLR2 and 6 [40]. Expression of the M-CSF receptor was detected in the CHME3 cells, by western immunoblot analysis [41]. Although the concept of microglial polarization has been recently challenged [42], the expression of specific M1- (like CD40 and CD86) and M2- (like CD163 and CD206) polarization markers has been detected in the CHME3 cells $[37,39,43]$. The majority of the CHME3 cells (approximately 30-60\%) indeed express the CD40 antigen, whereas other markers (i.e., CD86; CD80; MHCII) were found in approximately $5-20 \%$ cells under basal conditions [37, 43]. Interestingly, differential expression of these markers was linked to different microglial activation states and functions. The stimulation of CHME3 cells with the amyloid beta peptide, $A \beta_{1-42}(1 \mu \mathrm{g} / \mathrm{ml}$, consisting mainly of monomers and dimers), reduced the expression of $\mathrm{CD} 40$, leaving largely unaffected the levels of other polarization markers [43]. Interestingly, microglial cells phagocytosing $A \beta_{1-42}$ mostly expressed M2-polarization markers, i.e., CD163 and CD206 [43]. At higher concentrations $(10-100 \mu \mathrm{g} / \mathrm{ml})$, the $A \beta_{1-42}$ tended to form larger oligomers, together with fibrillary aggregates [44]. In these conditions, the $A \beta_{1-42}$ peptide $(10 \mu \mathrm{g} / \mathrm{ml})$ seemed to favor microglial M1-polarization, as demonstrated by increased expression of CD40 and CD11b, and no 
substantial effects on the expression levels of several M2-polarization markers, including CD163, CD206, CD200R (a deactivating receptor) and CD33 (an endocytic marker) [39]. When cultured in presence of neuronal precursor cells (NPCs), the CHME3 significantly upregulated the expression of MHCII antigens (up to 30\%) together with the M2-polarization marker, CD206 [37]. Finally, treatments of CHME3 with conditionedmedium (CM) harvested from different glioma cell lines, i.e., U251, U87, LN229, U373, and A172 cells, resulted in the down-regulation of M1-specific (TNF $\alpha$ and CXCL10) and up-regulation of M2-specific polarization markers (IL-1 receptor antagonist and CD204) [41]. These authors further show that M-CSF released by glioma cells increased the pro-angiogenetic properties of microglial CHME3 cells with no significant effects on their polarization [41].

The research group of Prof. Krause (Department of Pathology and Immunology; Faculty of Medicine, University of Geneva), i.e., the depositor of the HMC3 (ATCC ${ }^{\circ} \mathrm{CRL}-3304$ ) cell line, further characterized the antigenic profile of the HMC3 cells by immunofluorescence staining for different myeloid lineage markers and for resting/activated microglial receptors. The authors reported that "resting HMC3 cells were strongly positive for the microglia/macrophage marker IBA1 (Fig. 1a), positive for the endotoxin receptor CD14 (Fig. 1b), but negative for the astrocyte marker GFAP (Fig. $1 c$ and d). Markers of activated microglia, namely MHCII (Fig. 1e and f), CD68 (Fig. $1 g$ and h) and CD11b (Fig. $1 i$ and $j$ ), were negative in resting HMC3 cells, but upregulated after activation by IFNy $(10 \mathrm{ng} / \mathrm{ml}$, $24 h$ )", page 575 [20]. Of note, the same description is reported in the data sheet of the HMC3 (ATCC ${ }^{\circ} \mathrm{CRL}-3304$ ) cell line. In our opinion, data shown by $\mathrm{Li}$ and colleagues in figure 1 of their paper [20] seem to indicate a similar low level of expression of both IBA1 and CD14 in the HMC3 cells under resting conditions. Moreover, in contrast with the original characterization [17], resting HMC3 cells were found negative for the expression of CD68 and CD11b, albeit these activation markers were induced by IFN $\gamma$. Taken together, these data suggest that the HMC3 may have lost some of the original antigenic characteristics [17]. However, it should be noted that the expression level of CD68 in this culture appears to vary in function of the specific primary antibody adopted, as discussed above. Consistently, a basal expression of CD68 was observed in the HMC3 cells (provided by Prof. Krause) by flow cytometric analysis using a specific antibody produced by BD-Pharmingen, CA, USA [29]. In this study, it was also confirmed that resting HMC3 cells express IBA1, and at very low level other myeloid markers, including MHCII (HLA-DR), CD14, and CD45 [29]. The latter is a transmembrane glycoprotein expressed by cells of hematopoietic origin, except erythrocytes. It has frequently been used to distinguish CNS resident microglia $\left(\mathrm{CD} 11 \mathrm{~b}^{+} / \mathrm{CD} 45^{\text {low }}\right)$ from peripheral macrophages $\left(\mathrm{CD}_{11} \mathrm{~b}^{+} / \mathrm{CD} 45^{\text {high }}\right)$ [45]. However, it has recently been shown that the expression level of CD45 on microglial cells may vary under pathological conditions, and novel specific microglial biomarkers have been identified [1,2].

In addition, the cell line was characterized for the expression of several chemokine receptors. Particularly high levels of the CCR3, CXCR1, and CXCR3 receptors were expressed by the CHME3 cells, whereas the CCR2 receptor was barely detected [38]. Compared to primary human microglial cells, harvested from adult human brain tissue, the expression pattern of chemokine receptors in the CHME3 cells was very similar, with CCR3, CXCR1, and CXCR3 mainly distributed on the cell surface, and CCR5 only detectable in intracellular vesicles. Moreover, 24-h treatments with the pro-inflammatory cytokines, TNF $\alpha(25 \mathrm{ng} / \mathrm{ml})$ or IFN $\gamma(200 \mathrm{U} / \mathrm{ml})$, induced a significant upregulation of CCR3 and a slight increase in the expression levels of CXCR3, suggesting a possible role of these receptors in CHME3 inflammatory activation [38]. These evaluations were performed by flow cytometry and, more importantly, all the antibodies used were specific for human antigens, i.e., no cross-reactivity with rodent antigens reported in their respective datasheets. This can be taken as an indirect evidence of the human origin of these cells, thus excluding hypothetical contaminations with rodent cells [19]. Analysis of the mRNA steady state levels largely confirmed cytometric observations and documented in addition a significant increase in the mRNA levels of CCR10 in response to TNFa. Though the CCR10 receptor protein could not be measured by flow cytometry (due to the lack of specific antibodies at that time), an indirect evidence of the expression of this receptor on the surface of the CHME3 cells was obtained by evaluating the migration capacity of the cells in response to IP-10 [38]. Noteworthy, it should be considered that in this study, the human primary microglial cells were maintained in medium containing GM-CSF (Leucomax, Norvartis), at final a concentration of $25 \mathrm{ng} / \mathrm{ml}$. Moreover, it is stated that the CHME3 cells were grown in the same conditions as primary cultures. Thus, it is possible that the expression profile of chemokine receptors reflects the exposure to this relevant growth factor. Consistently, it has been shown that the HMC3 cells express at high levels the CXCR1, CXCR3, and CCR5 chemokine receptors, albeit also in this study, the cells were maintained in a highly enriched medium and at higher (15\%) FCS concentrations [29]. In these conditions, the expression level of CCR2 was very low, whereas the HMC3 cells expressed 
at higher levels, other chemokines receptors, including the CX3CR1 [29]. The latter is currently regarded as a more specific microglial marker [2].

Finally, the expression of classic neurotransmitter receptors has been detected in resting CHME3 cells, with respect to the cholinergic receptor $\alpha 7 \mathrm{nAcR}$ [44]. Interestingly, the expression level of this receptor varied in response to different inflammatory stimuli, including an up-regulation with LPS treatments and down-regulation in response to $10-100 \mu \mathrm{g} / \mathrm{ml} \mathrm{A} \beta_{1-42}$. On the other hand, the observation of a direct inhibition of cFos expression obtained with dexmedetomidine, a specific $\alpha 2$ adrenergic receptor agonist, would suggest the presence of these receptors on the HMC3 cell membranes [32]. In addition, it has been documented the expression of functional neurotensin receptor 3 in the aliquot of cells named C13-NJ [46]. Accordingly, neurotensin stimulated microglial migration and cytoskeleton remodeling, via activation of ERK signaling.

\section{Functional properties \\ Cytokine and chemokine production}

A summary of the inflammatory mediators produced by the cell line is provided in Table 2. In agreement with the original characterization [17], the CHME3 cells were found to release sizable amounts of IL- 6 in the incubation medium, with a very low or undetectable secretion of other inflammatory molecules, including TNF $\alpha$, IL-1 $\alpha$, IL-1 $\beta$, and caspase-1 [47]. Consistently, the proportion of resting cells showing a positive immunoreactivity for IL-1 $\beta$ and its receptor, IL-1RI, was quantified as $2.9 \%$ and $12.5 \%$ of the total, respectively [36]. The production of TNF $\alpha$ was later estimated to be in the range of $4-28 \mathrm{pg} / \mathrm{ml}, 24 \mathrm{~h}$ after plating under basal conditions $[43,44]$. On the other hand, basal IL-6 production by CHME3 cells was far more abundant and varied between 20 and $950 \mathrm{pg} / \mathrm{ml}$ in serum free medium after 24-h incubation [36, 43]. Similar results with respect to IL- 6 and TNF $\alpha$ basal production were also reported by Liu J and collaborators [37]. Finally, it was detected under basal conditions, a marginal secretion of anti-inflammatory cytokines, including IL-10 (around $5.4 \mathrm{pg} / \mathrm{ml}$ ) [43], TGF $\beta 1$, and TGF $\beta 2$ [37].

Interestingly, the CHME3 cells responded to different pro-inflammatory stimuli with significant increases in the production of IL-6. Two- to four-fold increases of basal production were measured in response to the bacterial endotoxin (LPS), used in the concentration range of $10-5000 \mathrm{ng} / \mathrm{ml}$ [48]. Similarly, the $A \beta_{1-40}$ peptide, another peptide involved in the Alzheimer's disease pathogenesis [49], induced a two-fold increase of basal IL-6 production at $10 \mu \mathrm{M}$ and a 10-12-fold increase at 20-60 $\mu \mathrm{M}$. The effects of $A \beta_{1-40}$ were selective on the IL-6 pathway, and the secretion of other inflammatory mediators (i.e., TNF $\alpha$, IL- $1 \alpha$, IL- $1 \beta$, and caspase-1) was not modified [47]. However, while LPS did not affect cell viability, treatment with $A \beta_{1-40}$ significantly reduced CHME3 viability, assessed by the MTT reduction assay $[47,48]$. Consistently, the CHME3 microglial cells displayed a pro-inflammatory phenotype when co-cultured with human neuroblastoma cells SH-SY5Y stably expressing the amyloid beta precursor protein (APP) harboring the $\mathrm{APP}_{695}$ Swedish mutation $\left(\mathrm{SH}_{\text {swe }}\right)$ [50]. Similarly to wild type cells, the $\mathrm{SH}_{\text {swe }}$ cells can be differentiated into neurons by exposure to $10 \mu \mathrm{M}$ retinoic acid for 7 days. However, the $\mathrm{SH}_{\text {swe }}$ neurons produce increased amounts of immature APP, soluble APP, and the $\mathrm{A} \beta_{1-40}$ peptide than wild type cells, and this can explain their pro-inflammatory effects when co-cultured with CHME3 cells. Briefly, the CHME3 cells were found to express, at the mRNA levels, several inflammatory genes (i.e., iNOS, IL-1 $\beta$, TNF $\alpha$, IL-6, MHCII antigens, ARG1, and IL-10) when co-cultured with differentiated neuronal SH-SY5Y wild type cells for 24,48 , and $72 \mathrm{~h}$. These markers were significantly upregulated in presence of the $\mathrm{SH}_{\text {swe }}$ differentiated neuronal cells, with major modifications observed for IL- $1 \beta$ and IL- 6 gene expression at 72 h [50]. Interestingly, the expression of several microRNAs (miRNAs) implicated in microglial polarization (i.e., miR-155, miR-146a, and miR-124), together with their respective downstream signaling pathway, was modulated in the CHME3 cells co-cultured with $\mathrm{SH}_{\text {swe }}$ neuronal cells [50]. Conversely, the $A \beta_{1-42}$ peptide, at concentrations lower than $5 \mu \mathrm{g} / \mathrm{ml}$, did not exert any stimulatory effect on IL-6 production [36, 43], neither modified basal TNF $\alpha$ and IL-10 secretion by the CHME3 cells [43]. Only a modest increase of basal TNF $\alpha$ production (from $4 \mathrm{pg} / \mathrm{ml}$ to $6 \mathrm{pg} / \mathrm{ml}$ ) was observed in response to higher concentrations $(10 \mu \mathrm{g} / \mathrm{ml})$ of the $A \beta_{1-42}$ peptide [44]. With respect to IL- 6 production, IL- $1 \beta$ seems to be the most effective inducer, increasing by 50 times the basal release (when used at $50 \mathrm{ng} / \mathrm{ml}$, for $24 \mathrm{~h}$ ) [36]. On the other hand, IFNY per se displayed only modest stimulatory effects $[36,47]$. In contrast to what was observed in rodent models [51], IFN $\gamma$ did not modify the response of the CHME3 cells to $10 \mu \mathrm{M}$ $A \beta_{1-40}$ peptide [47], whereas it significantly increased the pro-inflammatory activity of IL-1 $\beta$ (both cytokines used in combination at $50 \mathrm{ng} / \mathrm{ml}$ ) [36]. Neither IL-1 $\beta$ nor IFN $\gamma$ per se affected microglia viability (MTT assay) [36, 47], albeit the cytokines used in combination significantly reduced cell viability [36]. Finally, a modest stimulatory effect on IL-6 production was observed in response to the $\alpha$-melanocyte stimulating hormone $(\alpha \mathrm{MSH})$, and this was potentiated by a specific receptor agonist [47]. The $\omega-3$ fatty acid, eicosapentenoic acid (EPA), displayed stimulatory effects 
only at lower concentrations $(5-10 \mathrm{nM})$, an effect that was reversed by cell exposure to $A \beta_{1-42}$ peptide [43]. Another relevant $\omega-3$ fatty acid, docosahexaenoic acid (DHA), did not show any significant stimulatory effect on IL-6 production [43]. In addition, the CHME3 cells were found to release other cytokines, including IL-12 and IFN $\gamma$, in response to LPS [52].

A potent inducer of CHME3 cell activation is the non-structural NS3 protein of the hepatitis virus C $(\mathrm{HCV}$ ). The recombinant $\mathrm{HCV}$ NS3 (at 2-20 ng/ml) promoted the upregulation and significantly increased the release of several cytokines, i.e., IL-1 $\beta$, IL- 6 , and TNF $\alpha$, and the chemokine IL-8 [40]. The effects of NS3 protein were mediated by binding to TLRs, as TLR2 and TLR6, followed by activation of downstream NFKB signaling pathway. TLR specific agonists inhibited the pro-inflammatory effect of the HCV NS3 protein by promoting the release of anti-inflammatory IL-10 [40]. Similarly, the mRNA levels of several cytokines, with both pro-inflammatory (IL-1 $\beta$, IL-6, and TNF $\alpha$ ) and anti-inflammatory (IL-4 and IL-10) activities, increased in response to microglial infection with the Japanese encephalitis virus (JEV) [53, 54], together with a significant up-regulation of type I interferon, IFN $\beta$. Increased levels of IFN $\beta$ mRNA were mediated by activation of the transcription factor IRF3 [55] and subsequent expression of IRF8 [53]. JEV-mediated microglial infection is also characterized by the induction of TRIM21, which exerts an inhibitory role on microglial antiviral responses [55]. In addition, a more comprehensive characterization of the dynamic changes occurring in the human microglial microRNAome and transcriptome in response to JEV infection can be found in the paper by Kumari and collaborators [54]. This study further extends previous observations, confirming the immune regulatory role of different microRNAs, i.e., miR-155 [53], miR-146a [56], and miRNA-432 [57]. Consistently, microarray data analysis showed the downregulation of STAT1 gene during JEV infection, which suggests impaired signaling downstream of cytokine receptors/JAK activation [58]. Thus, a complex interplay between miRNAs, transcription factors and mRNAs occur during JEV infection, contributing to the inhibition of microglial antiviral responses (as for example secretion of type I interferon) and facilitating viral replication in CHME3 cells.

The expression of different inflammatory molecules, including IL-1 $\beta$, IL-6, TNF $\alpha$, iNOS, vascular endothelial growth factor (VEGF), and TGF $\beta 1$, was documented, albeit only at the mRNA level, in the HMC3 cells [20, 21]. The expression levels of IL- 6 were reduced by silencing the isoform 4 of NADPH oxidase (NOX4), thus, suggesting that the endogenous production of free oxygen radicals is linked to basal expression of IL-6 [20]. The basal mRNA levels of other genes, i.e., iNOS, VEGF, and
TGF $\beta 1$, was unaffected by downregulation of NOX4. Consistently with data obtained using the CHME3 cells, the mRNA steady state level of the pro-inflammatory cytokines (IL-1 $\beta$, IL-6, and TNF $\alpha$ ) was modulated by a specific microRNA (miR-17, as discussed in more detail in the next section) [21]. In addition, it has been shown that the HMC3 cells (provided by Dr. J Pocock, University College of London) produce significant amounts of IL-6, together with several chemokines (i.e., CXCL10, CCL5, and CCL2) in response to human immunodeficiency virus (HIV) vector-transduced monocytoid cells (HIV-U937 cells). HMC3 microglial cells in contact with HIV vector alone responded with increased production of IL-6, CXCL10, and CCL5, albeit to a lower extent in comparison to activation with HIV-U937 cells [30]. Data presented in this paper confirm a basal production of IL-6 in HMC3 cells, together with sizable amounts of CCL5. Other cytokines, including IFN $\gamma$, IL-1 $\beta$, IL-4, and IL-10 were not detected [30]. The immunomodulating agent, teriflunomide, significantly reduced microglial inflammatory activation induced by HIV-U937 cells, whereas, monomethylfumarate (MMF) was less effective (only CXCL10 reduction at the highest dose tested). Both drugs were also able to inhibit cytokine release by microglial cells activated in response to the HIV-vector, with MMF displaying a more relevant effect. Interestingly, data obtained with the HMC3 cells were confirmed in primary cultures of human microglial cells (isolated from patients with intractable epilepsy), thus further supporting the relevance of this experimental model to study human microglial properties. Conditioned medium harvested from HMC3 cells exposed to HIV transduced monocytoid cells caused significant neuronal toxicity, whereas neuroprotection was observed with teriflunomide and MMF treatments [30]. However, Rawat and collaborators [59] questioned the use of human microglial cell lines, including the HMC3 cells, for the study of HIV pathogenesis due to the genetic manipulation caused by the immortalization procedure, the higher growth rate in comparison to primary microglial cells, and reduced HIV replication within these cells. These authors further characterized the human primary microglial cell model originally developed by Etemad and colleagues [29], thus deriving human microglial cell cultures by peripheral monocytes exposed to a cocktail of human recombinant cytokines (i.e., M-CSF, GM-CSF, NGF $\beta$, and CCL2). These cells were efficiently infected by HIV, and more importantly, supported long-term HIV infection promoting the release of infectious virions into culture media [59]. However, immortalized microglial cells were recently used to study HIV latency and its regulation. In this study, adult human microglial cells were immortalized using a combination of SV40 and hTERT; the latter reduced the rate of cell growth and 
basal microglial activation. Latently infected microglial cells displayed marginal expression of HIV, but can be promptly activated in response to different inflammatory stimuli (TNF $\alpha$, IL-1 $\beta$, and LPS) [19] On the other hand, CHME3 cells were used to test the translational efficiency of highly conserved elements on the HCV viral genome, i.e., the internal ribosome entry site (IRES) [60]. In this study, it was demonstrated that the ability of $\mathrm{HCV}$ to replicate in microglial cells, together with the property of IRES sequences to change in order to favor viral latency in the CNS and full replication in the liver. At variance of murine BV2 microglial cells, the CHME3 displayed increased resistance to the cytotoxic effects of 5Z-7-oxozeaenol, an inhibitor of TGF $\beta$-activated kinase 1 [61]. Finally, the CHME3 cells were used to identify molecular factors involved in Zika virus cell entry [62].

\section{Free oxygen and nitrogen species production}

Rodent microglial cells have been extensively characterized for their ability to produce reactive oxygen and nitrogen species, including $\mathrm{NO}$ mainly generated in the $\mu \mathrm{M}$ range by the prompt upregulation of iNOS in response to different pro-inflammatory stimuli. In contrast, only a small proportion (around 16\% of the total) of CHME3 cells was found to express iNOS $24 \mathrm{~h}$ after the plating under basal conditions (Table 2). Moreover, the total fraction of iNOS positive cells did not vary in response to the $A \beta_{1-42}$ peptide, even though a larger percentage of iNOS ${ }^{+} / \mathrm{A} \beta_{1-42}{ }^{+}$cells was detected at different time points (24-96 h incubations) [36]. These data would therefore suggest that the expression of iNOS in the CHME3 cells is related to their phagocytic capacity [36]. Detection of iNOS mRNA was shown in CHME3 cells co-cultured with differentiated SH-SY5Y neuronal cells [50], as well as in resting HMC3 [20] (as discussed above). However, NO production was not evaluated in these studies, neither in other published articles. Thus, there are no available evidence that the CHME3/HMC3 cells release NO under basal conditions or in response to inflammatory activators. On the other hand, it has been shown that the HMC3 cells spontaneously release sizable amount of free oxygen radicals (ROS) ([20]; Table 2). Noteworthy, cells were maintained according to the original protocol [17], in EMEM supplemented with $10 \% \mathrm{FCS}$, and antibiotics, at $37{ }^{\circ} \mathrm{C}$ in a $10 \% \mathrm{CO}_{2}$ humidified atmosphere. The production of ROS appeared to be mediated by NOX4 activity, and it was not significantly modulated by short term $(2 \mathrm{~h})$ treatments with IFN $\gamma$ [20]. Consistently, Jadhav and collaborators have shown a basal production of ROS by the HMC3 cells, with a modest (0.15-fold) increase induced by treatment with the HIV TAT-C protein ([21]; Table 2). Specifically, the viral protein was also able to reduce the expression of miR-17 in the HMC3 cells, an effect that paralleled with increased expression of the NOX2 and NOX4 enzymes. In fact, the 3' untranslated regions (UTRs) of both genes contain multiple binding sites for miR-17. Thus, miR-17 overexpression in HMC3 cells significantly reduced the expression of NOX2 and NOX4 proteins, whereas the transfection of anti-miR17 oligonucleotides displayed opposite effects on both enzyme expression and activity. Similar effects were also observed with respect to the expression of certain pro-inflammatory cytokines, i.e., IL-1 $\beta$, IL- 6 , and TNF $\alpha$ [21]. Interestingly, this research group had previously shown the ability of the HIV TAT-C protein to modulate the expression of miR-32 and TRAF3 in human microglial cells [63]. However, in this previous study, the authors employed the CHME3 cells (no source is listed in the paper), whereas later used the HMC3 cells provided by Prof. Krause [21]. Notably, in both cell lines, the HIV TAT-C protein had similar pro-inflammatory effects, by promoting microglial activation through regulation of micro RNA expression.

\section{Phagocytosis}

As discussed above, the HMC3 cells displayed lower phagocytosis activity in comparison to the primary culture used for the immortalization procedure [17]. The phagocytic ability of the CHME3 cells was later confirmed by exposing the culture to fluorescent $A \beta_{1-42}$ (at concentrations $<5 \mu \mathrm{g} / \mathrm{ml})[36,39,43]$. In a first study, it has been shown that the CHME3 cells were able to uptake $A \beta_{1-42}$ aggregates. The activity was particularly relevant at $5 \mu \mathrm{g} / \mathrm{ml}$ concentrations of $\mathrm{A} \beta_{1-42}$, despite a significant increase in cell toxicity [36]. As discussed above, phagocytic CHME3 cells displayed mostly M2polarization markers, including CD163 and CD206 [43]. Pre-incubation with IFN $\gamma$ alone or in combination with IL- $1 \beta$, further increased the $A \beta_{1-42}$ phagocytic capability of the CHME3 cells. In contrast, IL-1 $\beta$ per se had no effects on the CHME3 phagocytic activity, despite its relevant stimulatory action on IL-6 production (as discussed above) [36]. Taken together, these data suggest that IFN $\gamma$ and IL-1 $\beta$ may selectively modulate certain microglial functions, whereas in combination can synergistically act to promote both cytokine secretion and phagocytosis. Interestingly, the $A \beta_{1-42}$ phagocytic ability of the CHME3 cells was significantly increased by treatment with the $\omega-3$ fatty acids, DHA, and EPA [43], and by the pro-resolving inflammatory lipid mediator, maresin (MaR1), a derivative of DHA, in short-term incubation (1-6 h) experiments [39]. In the CHME3 cells, phagocytosis was also assessed by exposure to latex beads and subsequent quantification by flow cytometry and confocal microscopy [37]. The phagocytic ability of microglial cells significantly increased when cells were cultured in presence of human NPCs [37]. Interestingly, 
it has been recently shown that the CHME3 cells can reduce the extent of extracellular accumulation of sAPP $\alpha$ and $A \beta_{1-40}$ when co-cultured with differentiated $\mathrm{SH}_{\text {swe }}$ neuronal cells [50]. However, the ability of microglial cells to clear these neuronal products appeared to be saturated after $24 \mathrm{~h}$, with accumulation observed after longer incubations $(48-72 \mathrm{~h})$. In co-culture with $\mathrm{SH}_{\text {swe }}$ neurons, CHME3 microglial cells progressively up-regulated senescence markers, an effect that can possibly explain the reduced efficiency in the $A \beta$ clearance [50]. Noteworthy, the CHME3 microglial cells were also able to efficiently internalize exosomes released from differentiated neuronal cells. In this regard, exosomes derived from $\mathrm{SH}_{\text {swe }}$ neurons were characterized for a more electron dense content in comparison to exosomes released by wild type differentiated SH-SY5Y cells, and more importantly for their enrichment in miRNAs involved in inflammatory processes. Interestingly, when transferred to microglial cells, neuronal exosomes tended to co-localize with lysosomes. However, reduced lysosomal co-localization was observed when microglia were treated with $\mathrm{SH}_{\text {swe-exosomes in comparison to their wild }}$ type counterpart, thus suggesting dysfunctional lysosomal activity in microglial cells. Reduced lysosomal function can affect the rate of protein degradation by microglia, thus favoring $A \beta$ accumulation. In addition, exosomes derived from $\mathrm{SH}_{\text {swe }}$ cells were more toxic than those released by $\mathrm{SH}$ wild type cells, and microglial cells appeared to be activated in response to $\mathrm{SH}_{\text {swe }}$-exosomes [50]. Finally, it has been shown that the HIV TAT-C protein is efficiently internalized by the CHME3 cells, and can be detected within cell nuclei [63].

Consistently, the HMC3 cells were also found to have phagocytic properties [29]. In this study, the HMC3 cells were exposed to tetramethylrhodamine (TRITC)-labeled Staphylococcus aures, and phagocytosis was assessed by flow cytometry and confocal microscopy. The HMC3 displayed a significant capacity to uptake the bacterial particles, with two distinct populations indeed detected by flow cytometry. However, the overall phagocytic activity of HMC3 cells was lower if compared to peripheral dendritic cells [29].

\section{Migratory capacity and secretion of matrix metalloproteases}

It is currently known that chemokines play an important role in the regulation of myeloid cell function, particularly in the control of cell migration within tissues during inflammation, but also in development and tissue repair [64]. In particular, chemokines can regulate macrophage/microglia migration to the site of inflammation and in the CNS; they mediate the crosstalk with different cell types, for example, between microglia and neurons or astrocytes [65]. Accordingly, the expression of specific chemokine receptors was observed in both the CHME3 and the HMC3 cells, with a similar pattern $[29,38]$. Consistently, the CHME3 cell were able to migrate in response to different chemokines (i.e., MCP-1, MIP-1 $\alpha$, MIP-1 $\beta$, RANTES, IL-8, and IP-10) [35], albeit IP-10 seemed to reduce cell viability, measured by MTT assay [38]. Furthermore, matrix metalloproteases (MMPs) are important enzymes that favor the remodeling of the extracellular milieu, thus increasing immune cell motility and migratory capability [66]. Consistently, it was shown that the CHME3 cells can secrete in the incubation medium sizable amounts of MMP2 under basal conditions [67]. The release of MMP2 could be augmented by treatment with different human chemokines, including MCP-1, MIP-1 $\beta$, RANTES, and fractalkine (albeit to a lower extent) or in response to IL-1 $\beta$ (1-50 ng/ml). Chemokines were also able to increase the release of specific tissue MMP inhibitors, namely TIMP1 and 2, by the CHME3 cells [67]. A modest release of MMP9 was detected by zymography (since specific ELISA was unavailable, at that time). In addition, MMP activity (measured by zymography) was further increased by different chemokines, particularly MCP-1 and IL-8, and by treatment with TNFo (1$10 \mathrm{ng} / \mathrm{ml}$ ). This study, however, showed a certain degree of variability in the CHME3 responses, with functional effects of some chemokines observed in some experiments but not in all [67]. Moreover, the CHME3 cells released increased amounts of MMP-1 and MMP-3 in response to CM, harvested from human peripheral blood monocytes infected with Mycobacterium tuberculosis (coMTb), in a concentration and time-dependent manner [68]. The stimulatory effect of coMTb was mediated by activation of p38 MAPK, but possibly involved other kinase signaling pathways, including ERK and AKT. Interestingly, basal ERK activity was detected in CHME3 cells [68]. In addition, the CHME3 cells express ADAMTS-13, an enzyme belonging to the ADAMTS family of metalloproteases and mainly synthesized in the liver [69]. The expression level of ADAMTS-13 in the CHME3 cells was lower in comparison to other human brain cell lines, including the neuroblastoma SH-SY5Y cells, the glioblastoma U373 cells, and the human brain endothelial cells, hCMEM/D3. Moreover, the levels of ADAMTS-13 were significantly reduced by treatments with IL-1 $\beta$ in the U373 cell line, whereas a trend towards reduction was also observed in the CHME3 cells. Other cytokines, including IL- 6 and TNF $\alpha$, had no inhibitory effects [69].

\section{Other properties}

The CHME3 cells express different isoform of lipooxygenase (LOX) enzymes, including the 15-LOX-2 and the 
5-LOX. Accordingly, a basal production of pro-resolving inflammatory mediators have been observed, including lipoxin A4 (LXA4, approximately $250 \mathrm{pg} / \mathrm{ml}$ ) and resolving D1 (RvD1, approximately $200 \mathrm{pg} / \mathrm{ml}$ ) [44]. In addition, the CHME3 cells have been also characterized for their ability to produce neurotrophic and growth factors. A basal release of brain derived neurotrophic factor (BDNF) was assessed and quantified within the range of

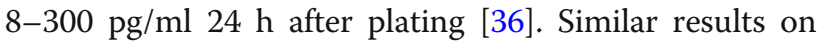
basal BDNF production were also later shown [37]. Interestingly, the $A \beta_{1-42}$ peptide $(5 \mu \mathrm{g} / \mathrm{ml})$ significantly reduced the release of BDNF by CHME3 cells, an effect that can potentially exacerbate neuronal damage [36]. However, when tested at lower concentrations, the $A \beta_{1-}$ 42 peptide did not modify the secretion of BDNF [36, 43]. Interestingly, the release of BDNF was augmented by treatment with the $\omega-3$ fatty acid EPA, whereas DHA had no significant stimulatory effect [43]. CHME3 cells treated with glioma $\mathrm{CM}$ were able to release the VEGF-A together with the insulin-like growth factor binding-protein 1 . Both factors were implicated in the pro-angiogenetic effects of microglial cells [41].

The cell line was characterized for the ability to influence the proliferation of other cells, including NPCs, endothelial cells, and lymphocytes. An important cross-talk between microglial CHME3 cells and NPCs, derived from 5 to 7.5 weeks old human embryonic CNS tissues, was found using in vitro co-cultures [37]. In this experimental paradigm, microglial CHME3 cells significantly increased the metabolic activity of NPCs and reduced cell death. In addition, the CHME3 cells significantly sustained NPC proliferation, inhibiting their differentiation towards the neuronal and astrocyte lineage. This effect was indicated by a lower percentage of PSA-NCAM $^{+}$(polysialylated neural cell adhesion molecule) and tubulin $\mathrm{III}^{+}$cells on one hand, and lower counts of positive cells for the glial precursor markers, A2B5 and GFAP, on the other hand. Accordingly, the percentage of nestin positive cells, indicating the presence of undifferentiated NPCs, increased in presence of microglial CHME3 cells added to NPCs during the differentiation protocol. It was speculated that the inhibitory effect of CHME3 cells on NPC differentiation was mediated by the abundant secretion of IL-6 in the incubation medium [37]. Interestingly, when co-cultured with CHME3 cells, NPCs increased the expression of CD200, whereas the microglial cells upregulated the synthesis of its specific receptor. On the other hand, NPCs significantly increased the rate of microglial proliferation and the production of TGF $\beta$, with a modest increase of IL- 6 and a reduction of BDNF release by CHME3 cells [37]. Despite these data on IL-6 and BDNF, in general, pro-survival and anti-inflammatory effects were observed in the interaction between NPCs and microglial cells in vitro, supporting a possible neuroprotective role of human NPC-based therapies. The medium collected by CHME3 cells exposed to glioma U87 CM increased the ability of tube formation of human umbilical vein endothelial cells, and this pro-angiogenetic effect was more evident in comparison to the supernatant of resting CHME3, i.e., not exposed to glioma CM [41]. In addition, a modest, albeit not significant, stimulatory effect on lymphocyte proliferation was observed in vitro using the HMC3 cells [29]. Finally, the electrophysiological properties of the human microglial clone 3 cells have been described by Nicholson and Randall [70]. In this research paper the cell line is indicated under the acronym of C13-NJ. Cells showed a mean membrane capacitance of $20.7 \pm 0.8 \mathrm{pF}$, and a mean resting potential $-49 \pm 4 \mathrm{mV}$. In addition, the cells exhibited depolarization-induced inward currents, compatible with the expression of $\mathrm{Na}_{\mathrm{v}} 1.5$ sodium channel. However, no significant changes in these sodium current properties were observed in response to 12 -h treatments with LPS $(1 \mu \mathrm{g} / \mathrm{ml})$ and $A \beta_{1-42}(10 \mu \mathrm{M})$. Interestingly, these data are in contrast with evidence obtained using rat microglial cultures, further suggesting the importance of human microglial experimental models.

\section{The human microglial CHME-5 cell line}

The HMC3 cell line has been widely used under the denomination of human microglial CHME- 5 cell line. A historical reconstruction of the distribution process of the CHME- 5 cell line across different laboratories, based on published articles, is presented in Fig. 2. From this schematic, it appears that the cell line was originally distributed under the name of CHME-5 and used in several publications between the years 1995 and 1999. Later on, the CHME- 5 cells have been mainly distributed by the laboratory of Prof. Talbot, University of Quebec, Montreal, Canada. Interestingly, the cell line was used in one publication under the name of $\mathrm{C} 13-\mathrm{NJ}$ [46] and distributed under the name of CHME-5 cells [71]. A number of publications have not cited the source of their cell samples whilst others received the cells from academic institutions for which publication records are not available. This may suggest that the cell line was distributed wider than it may be deducted from published articles.

The CHME-5 cells displayed same morphological $[72,73]$ and immunological properties [74], i.e., abundant production of IL- 6 under basal conditions. These early reports showed the ability of CHME- 5 cells to perform phagocytosis of latex beads, yeast, and zymosan particles [72, 74]. Moreover, the CHME-5 cells were characterized for a high rate of oxygen consumption [73, 75] and excessive production of ROS [76] under basal conditions. The CHME- 5 cells were resistant to heat shock stress, via increased expression of 


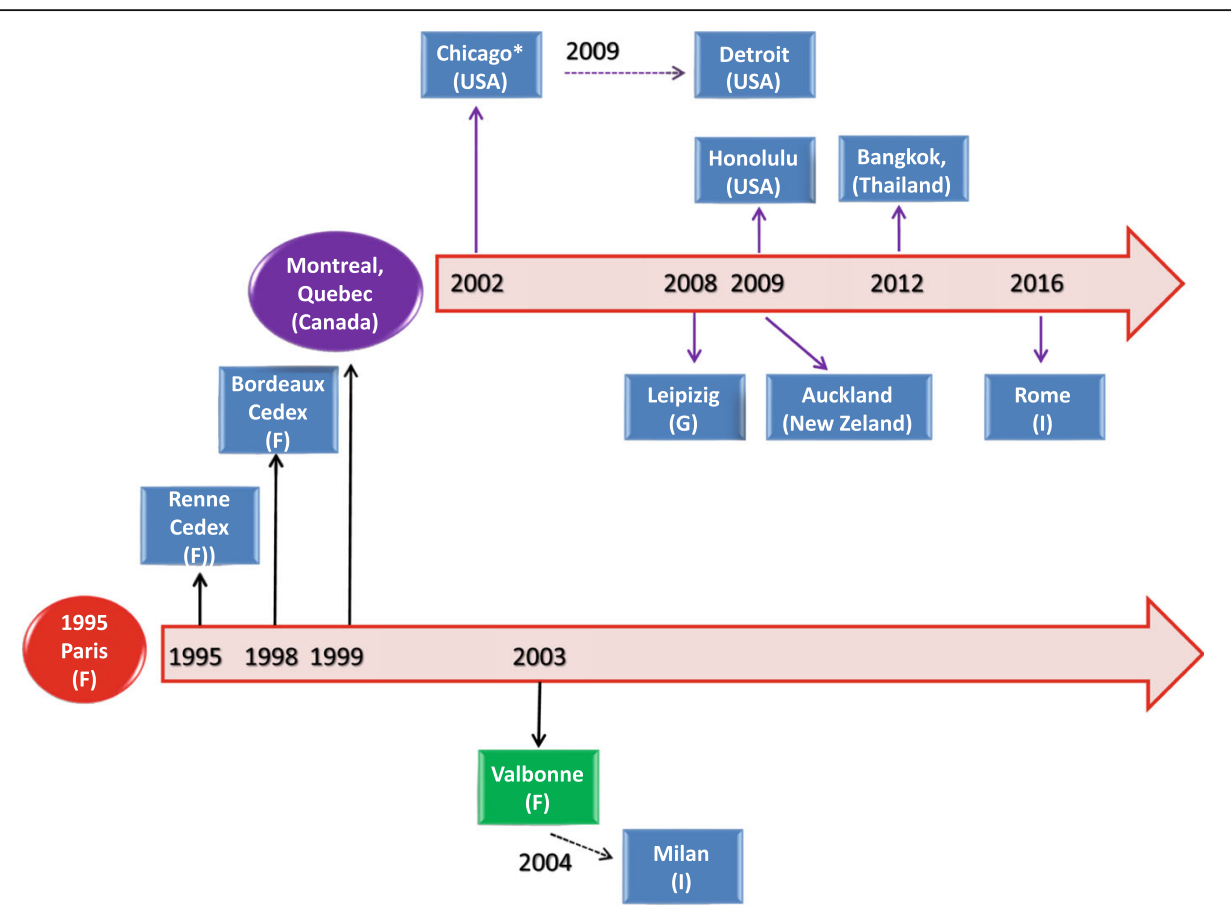

Fig. 2 Historical reconstruction of the distribution process of the human microglial CHME-5 cell line. The human microglial CHME-5 cell line was developed in the laboratory of Prof. M Tardieu, Paris, in 1995 (red circle). As shown in the picture, CHME-5 cells have been distributed worldwide (blue boxes). Same cells were used with the acronym C13-NJ cells (green box). Distribution followed two main pathways, either directly from Prof. Tardieu's laboratory (black thick arrows) or indirectly by the first recipient laboratory (black dotted arrows). Since 2002, the laboratory of Prof. Talbot, University of Quebec, Montreal, Canada, (purple circle), appears to be the main distributor of the CHME-5 cells. In addition, we identified several studies (not reported in the schematic), in which the CHME-5 cells were used without any indication of the source. Moreover, other laboratories received the cells from academic institutions for which publication records are unavailable.* Prof. Feinstein, University of Illinois, Chicago, USA, personal communication

heat shock proteins (Hsc70 and Hsp70), changes in their metabolism, mitochondrial function, and cytoskeleton remodeling [72, 77]. Accordingly, co-culturing of CHME-5 cells with rat $\mathrm{C} 6$ glioma cells promoted the relocation of the heat shock protein Hsp60 to the nucleus together with transient changes in microglial metabolism, including reduction of oxygen consumption, decreased mitochondrial enzymatic activities and membrane potential, increased lactate release, and reduction of ATP content [73]. In addition, the $\mathrm{C} 6$ glioma cells promoted microglial phagocytic activity and induced cytoskeleton modifications. Functional TREM2 receptors were detected in the CHME-5 cells [71]. Moreover, the CHME-5 cells expressed functional receptors for advanced glycation end-products (AGEs), named RAGEs [78]. AGEs increased ROS production in CHME- 5 cells and reduced cell viability [79]. Consistently, exposure of CHME-5 cells to AGEs triggered microglial activation, as suggested by increased expression of the glucose transporter GLUT-5, induction of MHCII antigens, and increased TNF $\alpha$ release [78]. The CHME-5 cells were resistant to low-energy electromagnetic field exposure and did not show any particular changes [80]. In contrast, increased ROS production, increased expression of GLUT-5 and MHCII antigens, together with a reduction in cell viability were observed in response to high dose ionizing radiations [81].

It was shown that the CHME- 5 cells were able to sustain the replication of the M-tropic HIV-1 strain $\mathrm{Yu}-2$ with a similar efficiency to human peripheral blood monocytes [82]. In addition, HIV-1 infected CHME-5 cells displayed extended survival and were resistant to cell death induced by LPS in combination with the protein synthesis blocker, cycloheximide. The cytoprotective effect induced by HIV infection was mediated by the HIV TAT protein and subsequent activation of survival signaling depending on the AKT pathway [82]. Since this initial observation, the human microglial CHME- 5 cell line has been widely used to study the biology of HIV-1, as documented by more than 15 publications [83-98]. The CHME- 5 cells were resistant to murine norovirus MV1 infection [99], whereas they were successfully used to culture Chlamydia pneumoniae isolated from post-mortem brain tissue of two patients affected by Alzheimer's disease [100]. The CHME-5 cells were susceptible to infection by human chikungunya virus [101], coronavirus (huCV) OC43 subgroup, and resistant to huCV-229E subgroup [102, 103]. In addition the CHME-5 cells could be infected by Zika virus that 
interferes with the mitotic fuse [104]. Interestingly, the CHME-5 cells were not able to sustain persistent huCV-OC43 infection, and responded to the acute infection with increased MMP activity and NO production [105]. In contrast to the HMC3/CHME3 aliquots, increased iNOS expression and NO production was detected also after overexpression of the endogenous retrovirus $\mathrm{W}$ envelope protein [88] and in response to a mixture of pro-inflammatory cytokines, including TNF $\alpha$, IL-1 $\beta$, and IFN $\gamma$ [106]. Furthermore, the CHME- 5 cells displayed increased arginase (ARG) activity in response to IL-4, which was significantly reduced by several antiretroviral drugs [106].

In contrast to all the evidence reviewed above, none of the following transcripts was detected in the CHME- 5 cells by semi-quantitative RT-PCR using human specific primers: IL- $1 \alpha$ and $\beta$, IL-6, IL-10, IL-12, TNF $\alpha$, TGF $\beta$, IFN $\gamma$, MIP-1 $\alpha$, and MCP-1 [105]. In addition, it has recently been shown by genotyping and amplification of a key human gene CyCT1 that several aliquots of CHME-5 cells (in use in different laboratories) are cross-contaminated by rat glioblastoma cells [19]. This observation further highlights the importance of authenticated cell lines as experimental models. This process, which has recently been performed by $\mathrm{ATCC}^{\circ}$ on the HMC3 cells, ensures for the origin of the cell line excluding cross contamination by other species. In addition, it allows researchers to control the genetic drift that can possibly occur with serial passaging of the cells, contributing to cell heterogeneity in cultures [107]. Genetic drift may explain the subtle differences observed among different laboratories using the same cell line.

\section{The HMC3 (ATCC ${ }^{\circledR}$ CRL-3304) cell line}

The human microglial cell line, HMC3 $\left(\mathrm{ATCC}^{\circ} \mathrm{CRL}-\right.$ 3304) (Lot/batch number 70002138), was delivered to our laboratory on June 7, 2017. A certificate of analysis was provided by $\mathrm{ATCC}^{\circ}$ for the specific lot of cells delivered, which certifies the human origin of the cells and the absence of cross contaminating cells from other species. The latter was confirmed by the cytochrome $\mathrm{C}$ oxidase I interspecies assay (COI analysis), a PCR based method to detect species specific variants of the COI gene and to rule out inter-species contamination. In addition, the certificate provides a human unique DNA profile, by short tandem repeats analysis, which can be useful to control the cell line for possible phenomena of genetic drift (see above). The HMC3 (ATCC ${ }^{\circ} \mathrm{CRL}-3304$ ) cells were immediately placed in liquid nitrogen as suggested by the distributor and 4 days later thawed following the instructions found in the data sheet. Additional information about the culturing conditions was obtained directly by the technical support of ATCC ${ }^{\bullet}$. Cell culture reagents [Eagle's Minimum Essential Medium (EMEM,
ATCC $^{\circ} 30-2003^{\mathrm{ma}}$ ) and Fetal Bovine Serum (FBS, ATCC $30-2020^{\text {mat }}$ )] were purchased from ATCC ${ }^{\natural}$, and cells were cultured in EMEM supplemented with 10\% FBS and antibiotics $(100 \mathrm{IU} / \mathrm{ml}$ of penicillin and $100 \mu \mathrm{g} / \mathrm{ml} \mathrm{of}$ streptomycin, Biochrom AG, Berlin, Germany). The entire aliquot of frozen cells was plated in one Corning ${ }^{\circ}$ T75 flask (Catalog \#430641) in $15 \mathrm{ml}$ complete growth medium (previously equilibrated for $2 \mathrm{~h}$ in the incubator) and incubated in a humidified atmosphere $(5 \%$ $\left.\mathrm{CO}_{2}\right)$ at $37^{\circ} \mathrm{C}$. This aliquot was numbered using an internal code as passage 1 . However, during this first passage in culture, we had to replace the growth medium more frequently than recommended to prevent excessive acidification. The $\mathrm{pH}$ of the incubation medium was measured at any medium change. Averaged $\mathrm{pH}$ value was $6.88 \pm 0.02$ (mean \pm SEM, $n=13$ ) after $24-48 \mathrm{~h}$ of incubation, regardless the number of cells. By avoiding the excessive acidification of the medium, cells remained viable and reached confluency within the times indicated by the ATCC's protocol. The technical support of ATCC $^{\circ}$ confirmed the tendency towards a quick acidification of the EMEM and more importantly reassured us on the healthy morphology of our cultures (Fig. 3). Cells were sub-cultured twice in order to have a homogenous population for the experiments and stored in frozen aliquots at passage 3 (p3). Mycoplasmas and the related Acholeplasmas (both referred as "mollicutes") represent a frequent source of cell line contamination. These bacteria pass through standard $0.22 \mu \mathrm{M}$ filter systems, their growth is not controlled by commonly used antibiotics and is not detectable under contrast phase microscopy. Thus, mollicutes can grow until extremely high titers without producing any turbidity in the supernatants. In addition, mycoplasma contaminations can significantly affect the biology of the cell culture, thus the quality of the experimental results [108]. Before freezing the cells, we excluded possible mycoplasma contaminations using the Venor ${ }^{\circ} \mathrm{GeM}$ Classic Mycoplasma detection kit, thus searching mycoplasma DNA in the incubation medium of almost confluent cultures at $\mathrm{p} 3$.

Based on our preliminary observations, we recommend to maintain the ATCC ${ }^{\circ} \mathrm{CRL}-3304$ cell line as follows: cells should be plated at the density of 20,000 cells $/ \mathrm{cm}^{2}$ in T75 flasks and kept in EMEM 10\% FBS and antibiotics (complete growth medium, $15 \mathrm{ml} /$ flask) by changing the medium the day after plating and every 24-48 h. Cells should be passaged twice a week, when reaching $90-95 \%$ confluency. Of note, the HMC3 cells can grow also in different media, including MEM (Biochrom, Germany) and in DMEM-F12 (Biochrom), with the addition of 10\% FCS (Biochrom) and antibiotics. These media showed a stable $\mathrm{pH}$ in the neutral range, thus were replaced every 2-3 days. Both media contain indeed higher concentrations of $\mathrm{NaHCO}_{3}$, i.e., 2.2- 

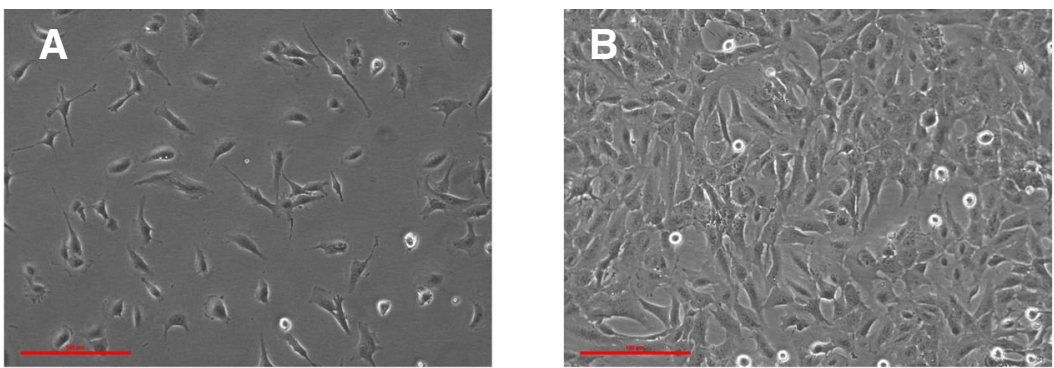

DAPI

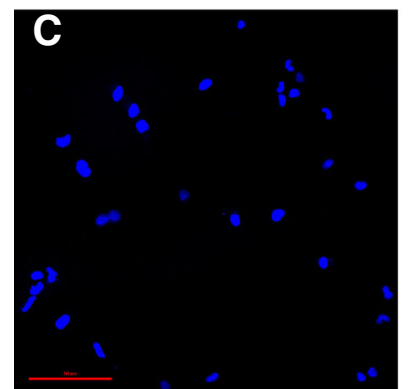

Phalloidin

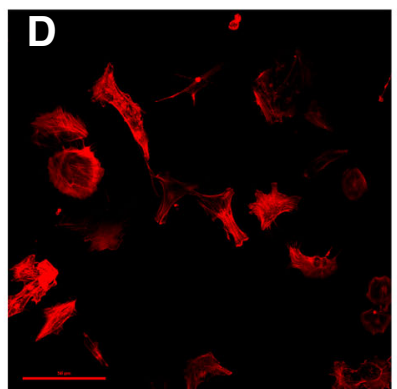

MERGE

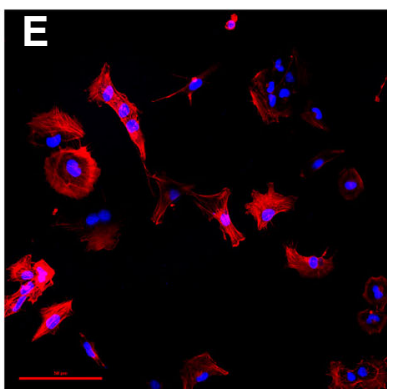

Fig. 3 HMC3 cell morphology and labeling of cytoskeletal F-actin filaments. a-b The human microglial cell line HMC3 as it was observed by phase-contrast microscopy at in vitro day 1 (a), and when cells reached the confluency (b). $\times 10$ magnification, scale bar $100 \mu \mathrm{M}$. $\mathbf{c}-\mathbf{e} \mathrm{A}$ representative example of confocal images $(1024 \times 1024$ pixels) acquired at $\times 20$ magnification with a confocal laser scanning system (A1+, Nikon). Cells were grown on glass coverslips for $24 \mathrm{~h}$, and their morphology was evaluated by labeling the cytoskeletal F-actin filaments with tetramethylrhodamine (TRITC)-conjugated phalloidin (red fluorescence). Cells were counterstained with the nuclear probe, 4',6-damidino-2phenylindole dihydrochloride (DAPI, blue fluorescence). The merged image is shown in (e). Scale bar $50 \mu \mathrm{M}$

$2.4 \mathrm{mg} / \mathrm{ml}$ vs $1.5 \mathrm{mg} / \mathrm{ml}$ dissolved in the ATCC ${ }^{\ominus}$ EMEM medium. MEM was complemented also with $1 \mathrm{mM}$ sodium pyruvate and $1 \mathrm{X}$ non-essential amino acids (Biochrom). When maintained in these media, cells divided more rapidly retaining their morphological features (not shown). For the phenotypical analysis, we plated the cells at 30,000 cells $/ \mathrm{cm}^{2}$ in T25 flasks and let them grow for 3 days until almost confluent. IFN $\gamma(10 \mathrm{ng} / \mathrm{ml})$, when used, was added in the last $36 \mathrm{~h}$. The expression of specific lineage markers was tested by immunocytochemistry and flow cytometry. The primary antibodies used for these evaluations are reported in Table 3. The expression of inflammatory genes was analyzed at the mRNA level by reverse transcription followed by realtime (Q)-PCR analysis, performed according to our standard protocol [109]. In brief, total cytoplasmic RNA was prepared from cells using TRIZOL reagent (Invitrogen) and $1 \mu \mathrm{g}$ aliquots were converted to cDNA using random hexamer primers and the ImProm-II Reverse Transcriptase kit (Promega). Q-PCRs were performed using the following cycling conditions: 35 cycles of denaturation at $95{ }^{\circ} \mathrm{C}$ for $20 \mathrm{~s}$; annealing at $60{ }^{\circ} \mathrm{C}$ for $30 \mathrm{~s}$; and extension at $72{ }^{\circ} \mathrm{C}$ for $30 \mathrm{~s}$; the Brilliant SYBR Green QPCR Master Mix 2X (Agilent); and the specific primers reported in Table 4. All the primer sets, except the one used for iNOS and COX2 expression, aligned only human sequences. Q-PCR reactions were carried out in a $20 \mu \mathrm{l}$ reaction volume in a MX3000P real time PCR machine (Stratagene). Relative mRNA concentrations were calculated from the take-off point of reactions (threshold cycle, $\mathrm{Ct}$ ) using the comparative quantitation method [109]. Ct values for $\beta$-actin (ACTB) expression served as a normalizing signal. ACTB was selected considering that it is a constitutively highly expressed gene in human microglia [2]. Q-PCR efficiency ranged between 94 and $106 \%$. At the end of Q-PCR, the products were separated by electrophoresis through $2 \%$ agarose gels containing $0.1 \mu \mathrm{g} / \mathrm{ml}$ ethidium bromide to ensure the product was the correct size. For functional experiments, cells were plated at 30,000 cells $/ \mathrm{cm}^{2}$ in 96 well plates $(100 \mu \mathrm{l} /$ well), let recover overnight and stimulated the day after in complete growth medium, i.e., EMEM containing with $10 \%$ FBS and antibiotics. IL-6 release was measured with a specific ELISA assay (R\&D Systems).

The morphology of a viable culture is shown in Fig. 3, i.e., 1 day after plating (Fig. 3a) and when cells reached confluency (day 3 post plating, Fig. 3b). In line with Etemad and colleagues [29], the HMC3 (ATCC ${ }^{\circ} \mathrm{CRL}-3304$ ) cells display a complex morphology, with both globular, 
Table 3 Antibodies and reagents used for immunocytochemistry and flow cytometry

\begin{tabular}{|c|c|c|}
\hline \multicolumn{3}{|l|}{ Immunocytochemistry } \\
\hline mAbs or immunostaining reagents & Concentration & Final dilution used \\
\hline $\begin{array}{l}\text { DAPI (4',6-diamidino-2-phenylindole, dihydrochloride) } \\
\text { (ThermoFisher Cat. N. D1306) }\end{array}$ & $5 \mathrm{mg} / \mathrm{ml}$ & $1 / 2000$ \\
\hline Rhodamine phalloidin (ThermoFisher Cat. N. R415) & $200 \mathrm{U} / \mathrm{ml}$ & $1 / 500$ \\
\hline $\begin{array}{l}\text { IBA1 } \\
\text { (Abcam Cat. N. ab15690) }\end{array}$ & $3.5 \mathrm{mg} / \mathrm{ml}$ & $1 / 100$ \\
\hline \multicolumn{3}{|l|}{ Flow Cytometry } \\
\hline mAbs & Optimal Ab volume per test $\left(1 \times 10^{6}\right)$ & Final dilution used \\
\hline PE-conjugated anti-GFAP (BD Pharmingen Cat. N. 561,483) & $5 \mu l$ & $1 / 40$ \\
\hline PE-conjugated anti-HLA-DR (BD Bioscience Cat. N. 562,304) & $5 \mu l$ & $1 / 50$ \\
\hline FITC-conjugated anti-CD14 (BD Pharmingen Cat. n 555,397) & $20 \mu \mathrm{l}$ & $1 / 10$ \\
\hline PE-conjugated anti-CD11b (eBioscience ${ }^{\mathrm{TM}}$ Cat. N. 12-0118-42) & $5 \mu l$ & $1 / 20$ \\
\hline PE-conjugated anti CD68 (BD Horizon Cat. N. 564,944) & $5 \mu l$ & $1 / 40$ \\
\hline FITC-conjugated anti-HLA-ABC (BD Biosciences Cat. N. 555,552) & $20 \mu l$ & $1 / 10$ \\
\hline
\end{tabular}

bipolar, and elongated cells detected in culture by rhodamine-phalloidin staining (Fig. 3c-e). We confirmed that cells are IBA1 positive (Fig. $4 \mathrm{~d}-\mathrm{g}$ ). Moreover, we detected at the mRNA level the expression of CX3CR1 and CSF1-R (Fig. 4g-h), together with other specific markers, comprised in the recently characterized microglial signature [2], i.e., P2RY12 and TMEM119 (Fig. 4h). The CCR2 transcript was undetectable (Fig. 4g), in line with previous observations [29, 38]. Consistently with the literature and the ATCC ${ }^{\circ} \mathrm{s}$ data sheet, the HMC3 cells were GFAP negative (Fig. 5a, i.e., the dark gray histogram completely overlaps the background histogram). The glioblastoma U373 cell line, kindly provided by Prof. Grassi (Institute of Physiology, Catholic University Medical School, Rome, Italy), was used as a positive control for the anti-GFAP antibody (Fig. 3a). The activation marker MHCII (HLA-DR in the figure) was negative under basal condition and upregulated in the $28 \%$ of the HMC3 cell population by IFN $\gamma$ treatment (36 h, $10 \mathrm{ng} / \mathrm{ml}$ ) (Fig. 5b). In addition, resting HMC3 cells were CD14 (Fig. 5c) and CD11b (Fig. 5d) negative, and these markers were not induced by IFN $\gamma$. With respect to CD14 expression, our results are in agreement with the original characterization [17] and the evaluation performed in flow cytometry by Etemad and colleagues [29]. Finally, the HMC3 (ATCC ${ }^{\circ} \mathrm{CRL}-3304$ ) cells expressed CD68 under basal conditions (Fig. 5e), in agreement with previous observations $[17,29]$. However, CD68 was expressed at low level indicated by a mean fluorescence intensity (MFI) of 3.3, and no further induction with IFN $\gamma$ was detected (MFI = 3.6). As shown in Fig. 6a, the HMC3 (ATCC ${ }^{\oplus}$ CRL-3304) cells were found entirely and homogenously positive for human leukocyte antigens $\mathrm{A}, \mathrm{B}$, and $\mathrm{C}$ (MHCI antigens). The antibody used for this analysis is specific for the human antigens and does not cross react with rat antigens. In addition, a HLA-B-specific amplification between the first and the third intron was carried out by PCR on genomic DNA samples, extracted by the HMC3 (ATCC ${ }^{\circ}$ CRL-3304) cells using the QIAamp ${ }^{\circ}$ DNA Blood mini kit (Qiagen, Hilden, Germany) [110]. The HLA-B locus-specific amplification was performed using the following validated primers: 5BIn1-57 forward primer (forward 5'-GGGA GGAGCGAGGGGACCG/CCA G-3'; intron 1 36-57) and 3BIn3-37 reverse primer (reverse 5'-GGAGGC ATCCCCGGCGACCTAT-3'; intron 3 37-59), yielding a 922 bp product [111]. The PCR reaction contained $100 \mathrm{ng}$ total DNA, 1X PCR buffer, $300 \mathrm{nM}$ of each primer, $1.25 \mathrm{U}$ AccuPrime $^{\mathrm{Tm}}$ PfX DNA Polymerase (Invitrogen Corporation) in $50 \mu \mathrm{l}$ final volume. After initial denaturation $\left(10 \mathrm{~min}\right.$ at $95{ }^{\circ} \mathrm{C}$ ), a total of 40 PCR cycles were conducted, using the following two-step PCR conditions: denaturation at $95{ }^{\circ} \mathrm{C}$ for $20 \mathrm{~s}$ and annealing/extension at $68{ }^{\circ} \mathrm{C}$ for $1 \mathrm{~min}$, in a MasterCycler Ep thermocycler ${ }^{\odot}$ (Eppendorf, Hamburg, Germany). The amplicons were separated by electrophoresis through 1.5\% agarose gels containing $0.1 \mu \mathrm{g} / \mathrm{ml}$ ethidium bromide. A human genomic DNA sample was provided by ViiV Healthcare Ldt. and used as positive Control for the amplification [112]. Data are presented in Fig. 6b. Taken together, this evidence further confirm the human origin of the HMC3 (ATCC ${ }^{\bullet}$ CRL-3304) cell line.

Consistently with the literature, the HMC3 (ATCC ${ }^{\circ} \mathrm{CRL}-$ 3304) cells produced sizable amounts of ROS. Reactive free radicals were measured using H2DCF-DA [2,7- dichlorodihydrofluorescein diacetate (Invitrogen)]. At the end of the experiment, the incubation medium was replaced by Hank's balanced salt solution (HBSS) containing $20 \mu \mathrm{M}$ of H2DCF-DA [20]. Cells were incubated at $37{ }^{\circ} \mathrm{C}$, in a 


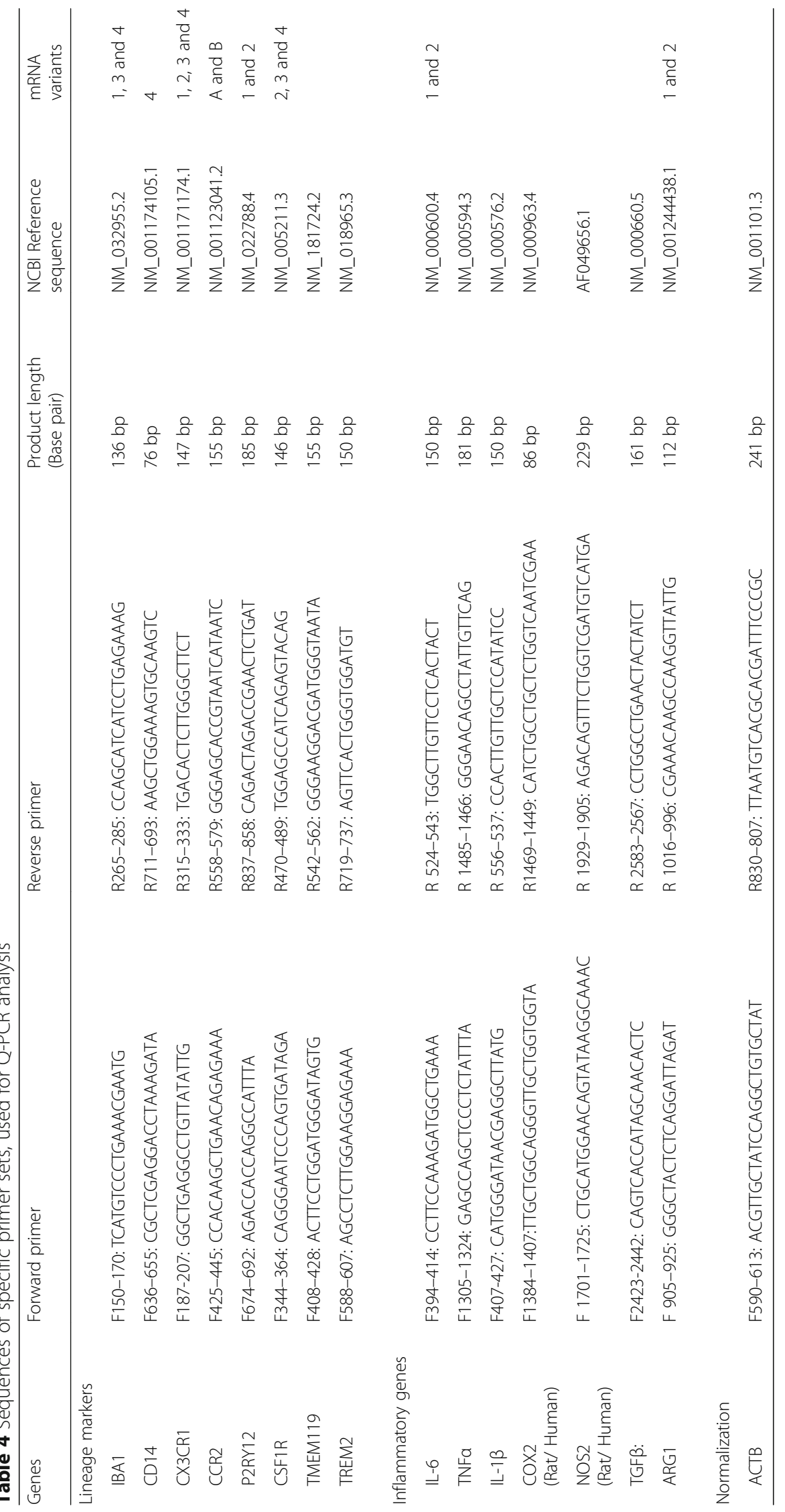



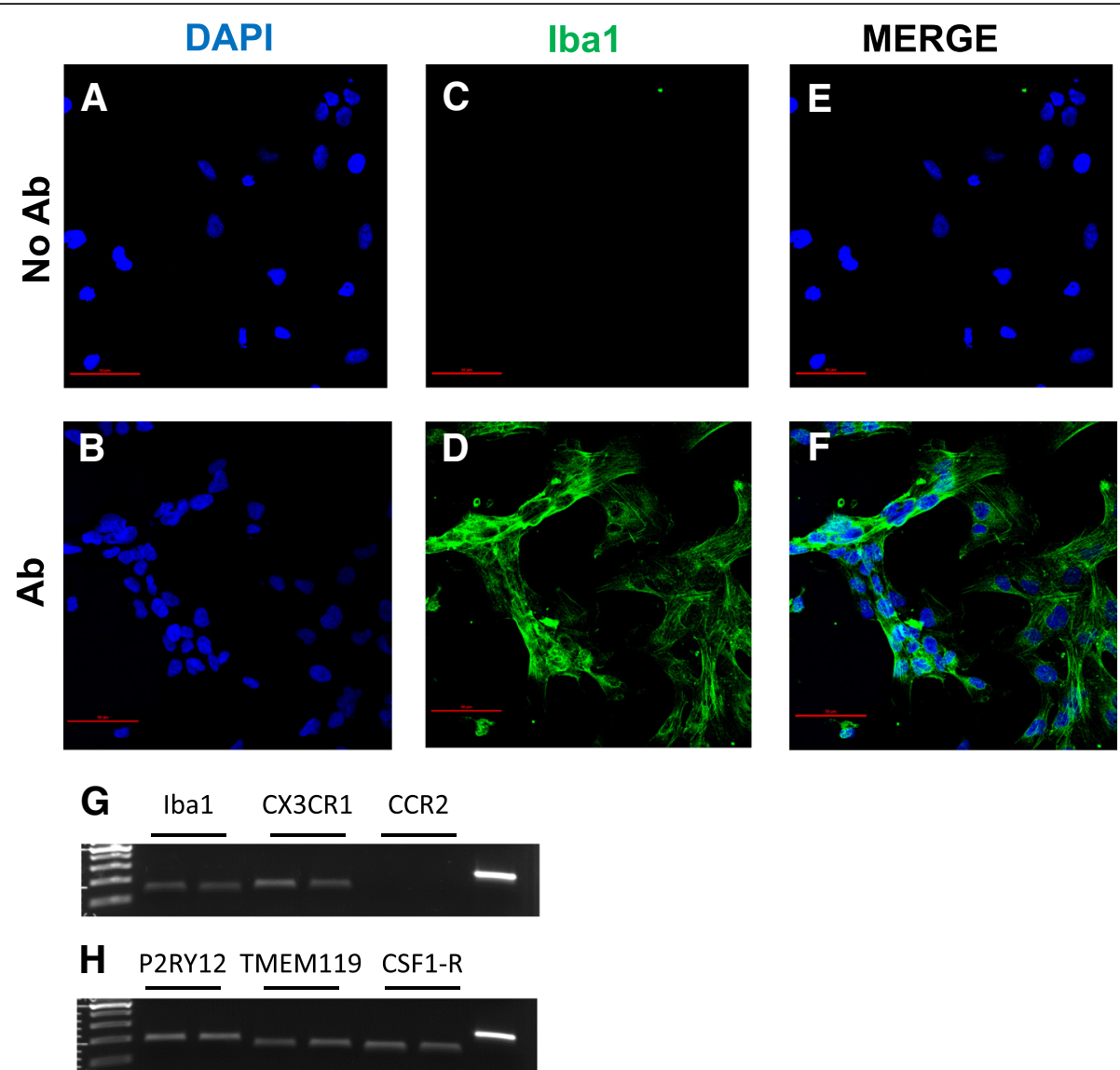

Fig. 4 HMC3 cell expression of microglial lineage markers. a-f Representative example of confocal images $(1024 \times 1024$ pixels $)$ acquired at $\times 20$ magnification with a confocal laser scanning system (A1+, Nikon). HMC-3 cells immuno-labeled for IBA1 (green fluorescence, $\mathbf{d}$, f) and DAPI stained (blue fluorescence, $\mathbf{a}, \mathbf{b}$ ) are shown. Merged images are shown in $(\mathbf{e}, \mathbf{f})$. Control experiments performed by omitting the primary antibody are shown in $(\mathbf{a}, \mathbf{c}, \mathbf{e})$. No green fluorescence was present $(\mathbf{c}, \mathbf{e})$, indicating neither spontaneous fluorescence nor nonspecificity of the secondary antibody. Scale bar $50 \mu \mathrm{M}$. g-h Total RNA was prepared from human microglial HMC3 cells $24 \mathrm{~h}$ after incubation in complete growth medium and retrotranscribed using random hexamers. Real time (Q)-PCR analysis for the mRNA levels of IBA1, CX3CR1, CCR2, P2RY12, TMEM119, and CSF1-R was carried out according to our standard protocols [109]. $\mathbf{g}$, $\mathbf{h}$ panels show a representative gel image of PCR products obtained at the end of the analysis from two different RNA samples for each condition. In the last line is shown the actin amplification, as positive control

humidified atmosphere with $5 \% \mathrm{CO}_{2}$, for $45 \mathrm{~min}$. The fluorescence signal due to H2DCF-DA oxidation within the cells was quantified using a microplate fluorescence reader (PerkinElmer Inc.), using $485 \mathrm{~nm}$ as excitation and $535 \mathrm{~nm}$ as emission wavelength [113]. Pro-inflammatory cytokines per se, at $10 \mathrm{ng} / \mathrm{ml}$, did not modify basal levels of ROS production, whereas IL-1 $\beta$ and TNF $\alpha$ each used in combination with IFN $\gamma$ slightly increased ROS production by HMC3 cells (0.1-0.2-fold increases), in line with previous observations [21]. However, this effect was not consistent among different experiments, carried out between passage 6 and 13. Interestingly, the production of ROS by HMC3 cells growth in either MEM or DMEMF12 was significantly lower, thus suggesting a less activated phenotype under basal conditions when kept in these media (not shown). In addition, we assessed the production of $\mathrm{NO}$ indirectly by measuring nitrite accumulation in the incubation media
[108]. Nitrite levels were undetectable under basal conditions and remained so after a 24-h treatment with different pro-inflammatory stimuli, including LPS, LPS/IFN $\gamma$, and IL-1 $\beta$, and TNF $\alpha$ used alone or in combination with IFN $\gamma$ (data not shown). Consistently, resting HMC3 (ATCC ${ }^{\circ}$ CRL-3304) cells did not express iNOS, neither its expression was induced by pro-inflammatory activation (Table 5). Conversely, we observed a basal expression of IL-6 (Table 5) in resting HMC3 cells, together with a sizable release of the cytokine in the incubation medium under basal conditions, i.e., $150 \mathrm{pg} / \mathrm{ml}$. The expression level of IL-6 increased in response to pro-inflammatory cytokines, particularly IL-1 $\beta$ in combination with IFN $\gamma$ (II, Table 5). In addition, the cytokine mixture (II) stimulated basal IL- 6 secretion by 20 -folds (data not shown). Other pro- and anti-inflammatory genes were studied at transcriptional levels under basal conditions and after 24-h 


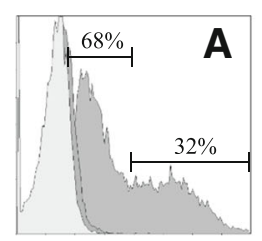

GFAP

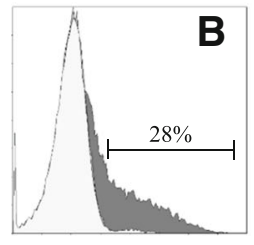

HLA-DR

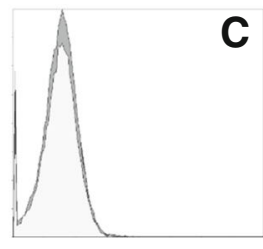

CD14

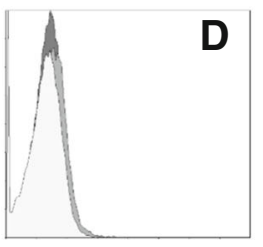

CD11b

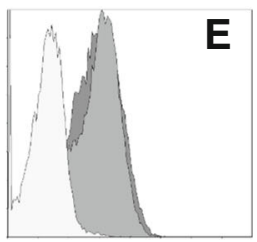

CD68

Fig. 5 Phenotypical characterization of HMC3 cells under basal conditions and in response to IFNץ. HMC3 cells were plated at the density of 30,000 cells $/ \mathrm{cm}^{2}$ in T25 flasks, and grown for 3 days when cells were almost confluent. In the experiments in which INFy was used, cells were stimulated for the last $36 \mathrm{~h}$. Controls did not receive any stimulus for the same time period ("resting" HMC3 cells). For detection of intracellular antigens, aliquots of $1 \times 10^{6}$ cells in $100 \mu$ were fixed using BD cytofix (BD Pharmingen) at $4{ }^{\circ} \mathrm{C}$ for 30 min, and permeabilized with BD FACS permeabilizing solution at $4{ }^{\circ} \mathrm{C}$ for $30 \mathrm{~min}$. Cells were then stained using the following antibodies: PE-conjugated anti Human GFAP mouse Mab, BD Bioscience (a), and PE-CF594-conjugated anti Human CD68 mouse Mab, BD Bioscience (e), according to the manufacturer's instructions. For the evaluation of surface antigens, aliquots of $5 \times 10^{5}$ cells in $100 \mu \mathrm{l}$ were directly incubated in PBS buffer containing the following antibodies: PE-CF594-conjugated anti Human HLA-DR mouse Mab, BD Bioscience (b); FITC-conjugated anti Human CD14 mouse Mab, BD Pharmingen (c); and PE-conjugated anti Human CD11b mouse Mab, E-Bioscience (d). Cells were analyzed by the 6-parameter (2 scatter and 4 fluorescence signals) Coulter Epics XL flow cytometer (Beckman-Coulter). Control histograms (white histograms) indicate level of cell autofluorescence in the emission wavelength that pertains the fluorochrome-conjugated Mab. Panel (a) shows expression of GFAP on HMC3 cells at passage 4 (dark gray), and on the human glioblastoma U373 cell line (light gray) that constitutively expresses GFAP. As autofluorescence signal in the two cell lines was similar, only one representative histogram is plotted in panel (a) (white histogram). As shown in this panel, the HMC3 cells stain negatively for GFAP (the dark gray histogram completely overlaps the background histogram), whereas the U373 cells express the target antigen. Two different populations expressing GFAP at different levels were identified (light gray plot): 68\% of the U373 cells express GFAP at low level (GFAP-dim), whereas 32\% of the cells express GFAP at higher level (GFAP-high). Panels (b-e) show results from HMC3 cells obtained at passage 7. In these panels, white histograms indicate cell autofluorescence, light gray histograms and dark gray histograms are representative of control ("resting") HMC3 cells and IFNy-treated HMC3 cells, respectively. Gating strategy: all analyses were obtained after gating according to morphological characteristics (not shown). As levels of autofluorescence did not change according to cell treatment, one representative example is plotted for each emission wavelength. Linear regions are used for calculating percentage of positive cells (plots A-B). Central tendency of CD68 expression on HMC3 cells in the different experimental conditions is represented by the mean fluorescence intensity (MFI, see text)

treatments with II (Table 5). The cytokine mixture promoted a significant up-regulation of IL-1 $\beta$, TNF $\alpha$, and COX2, leaving unmodified the expression of TGF $\beta$ and ARG1. In line with our data, it has been recently shown that the HMC3 (ATCC ${ }^{\circ} \mathrm{CRL}-3304$ ) cells express at the mRNA level several pro-inflammatory genes, including IL-1 $\beta$, TNF $\alpha$, IL-6, COX2, and in addition heme oxygenase-1 [31]. Interestingly, lumirubin, a photoisomer of bilirubin (generated during phototherapic treatment of neonatal hyperbilirubinemia), promoted microglial inflammatory activation as indicated by the upregulation of all these genes except COX2 [31]. Moreover, the pro-inflammatory effects of bilirubin photoisomers were more prominent on rat hippocampal slices, further highlighting relevant differences between human and rodent experimental models. Finally, increased expression and release of both IL-1 $\beta$ and IL-18 has been observed in the HMC3 (ATCC ${ }^{\circ} \mathrm{CRL}-3304$ ) cells by treatment with
$100 \mathrm{ng} / \mathrm{ml}$ LPS for $24 \mathrm{~h}$ followed by additional $30 \mathrm{~min}$ with $5 \mathrm{mM}$ adenosine triphosphate (ATP) [32]. Exposure of HMC3 (ATCC ${ }^{\circ}$ CRL-3304) cells to LPS/ATP was associated to increased expression of the intracellular NOD-like receptor 3 and activation of caspase 1, together with a significant increase of cFos nuclear protein levels. Pro-inflammatory effects of LPS/ATP were indeed reversed by knockdown of cFos. [32]. The treatment with LPS/ATP significantly affected microglial viability. All the effects of the LPS/ATP combination were reduced by the $\alpha-2$ adrenergic agonist, dexmedetomidine [32]. In these research papers, the HMC3 cells were maintained in MEM [31] or EMEM [32] with $10 \%$ FCS and antibiotics.

\section{Conclusions}

Evidence reviewed in the present paper suggest that the human microglial cell line clone 3 generated in the laboratory of Prof. Tardieu has been extensively 


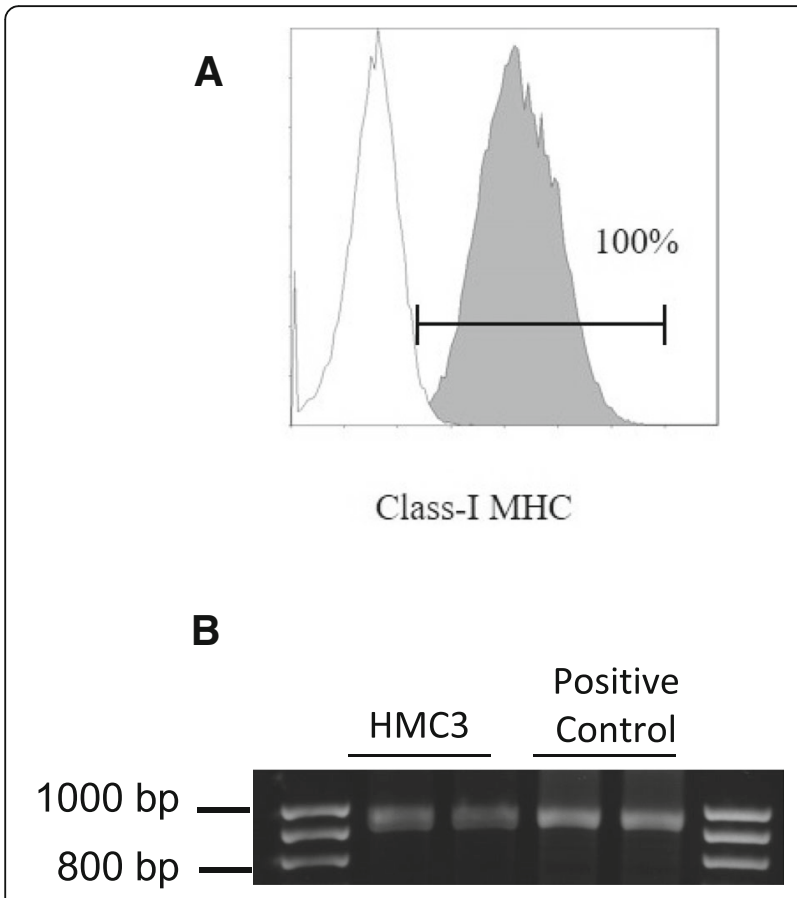

Fig. 6 Expression of the human class I MHC antigens on HMC3 cells. a HMC3 were plated at the density $30,000 \mathrm{cells} / \mathrm{cm}^{2}$ in T25 flasks, and grown for 3 days when cells were almost confluent. For the detection of class I MHC surface antigens, aliquots of $5 \times 10^{5}$ cells in $100 \mu \mathrm{l}$ were directly incubated with FITC-conjugated anti human HLA-ABC mouse Mab, BD Bioscience. This antibody is specific for human $\mathrm{MHCl}$ antigens, and does not cross react with rat $\mathrm{MHCl}$ antigens. Cells were analyzed by the 6-parameter (2 scatter and 4 fluorescence signals) Coulter Epics XL flow cytometer (BeckmanCoulter). Results from HMC3 cells at passage 8 are shown. Gating strategy: the analysis was obtained after gating according to morphological characteristics (not shown). Background histogram (white) indicates level of cell autofluorescence. A linear region was used for calculating percentage of positive cells. $\mathbf{b}$ Gel image of PCR products obtained at the end of a HLA Locus B specific amplification protocol. The $922 \mathrm{bp}$ amplicons were separated by electrophoresis through $1.5 \%$ agarose gels containing $0.1 \mu \mathrm{g} / \mathrm{ml}$ ethidium bromide. Lines 2-3 amplification products from genomic DNA extracted by HMC3 (ATCC ${ }^{\circledR}$ CRL-3304) cells; lines 4-5 amplification products from a positive control, i.e., an anonymous human genomic DNA sample provided by ViiV Healthcare Ldt

characterized, with respect to cell morphology, antigenic profile, and cell functions. However, cells were used under different denominations, i.e., CHME3, HMC3, C13-NJ, and CHME-5, which contributed to data fragmentation. In this regard, the experimental data reviewed in this article show that the cells, regardless the name adopted, retain a similar antigenic profile together with similar functional properties. The cells are capable of responding to a pattern of chemokines and inflammatory stimuli, regulating the expression of typical activation markers of microglia. Therefore, these cell lines should be regarded as a unique experimental model. Caution should be taken with data obtained
Table 5 Gene expression analysis of the HMC3 (ATCC ${ }^{\oplus} \mathrm{CRL}-$ 3304) cells

\begin{tabular}{lll}
\hline Gene & $\begin{array}{l}\text { Control (mean threshold } \\
\text { cycle, } C t)\end{array}$ & $\begin{array}{l}\text { II (Fold variation relative } \\
\text { to control) }\end{array}$ \\
\hline Pro-inflammatory genes & \\
IL-6 & $27.97 \pm 0.17(n=12)$ & $43.75 \pm 2.59(n=11)$ \\
TNFa & $32.50 \pm 0.20(n=12)$ & $5.37 \pm 0.45(n=11)$ \\
IL1 3 & $29.02 \pm 0.10(n=12)$ & $4.71 \pm 0.32(n=12)$ \\
COX2 & $33.00 \pm 0.50(n=9)$ & $2.51 \pm 0.46(n=9)$ \\
NOS2 & No Ct $(n=9)$ & No Ct $(n=9)$
\end{tabular}

Anti-inflammatory genes

$\begin{array}{lll}\text { TGF } \beta & 28.50 \pm 0.16(n=12) & 1.02 \pm 0.06(n=12) \\ \text { ARG1 } & 29.51 \pm 0.10(n=10) & 1.07 \pm 0.07(n=11)\end{array}$

using microglial cells named CHME-5, since it has been reported that several aliquots in use in different laboratories were cross contaminated by rat glioma cells [19]. Laboratories using the CHME- 5 cells should perform an authentication procedure to confirm the human origin. In this regard, the $\mathrm{HMC} 3$ (ATCC ${ }^{\circ} \mathrm{CRL}-3304$ ) cells present the advantage to have been authenticated by ATCC $^{\ominus}$ according to a complex procedure, including morphology evaluation, karyotyping, and PCR based approaches to confirm the identity of human cell lines and to rule out both intra- and inter-species contamination. In addition, we showed that the HMC3 (ATCC $\left.{ }^{\circ} \mathrm{CRL}-3304\right)$ cells retain most of the original antigenic properties and express also more specific microglial markers (recently identified) [2]. Resting cells produce significant amounts of ROS and IL-6. The latter can be further induced by pro-inflammatory cytokines (particularly IL-1 $\beta$ in combination with IFN $\gamma$ at $10 \mathrm{ng} /$ $\mathrm{ml})$. Evidence from the literature together with our original data may represent an important starting point for researchers that are planning to use this experimental model.

\section{Abbreviations}

ACTB: $\beta$-actin; ADAMTS: A disintegrin and metalloproteinase with thrombospondin motifs; APP: Amyloid beta precursor protein; ARG: Arginase; ATCC ${ }^{\oplus}$ : American Type Culture Collection; ATP: Adenosine triphosphate; $A \beta$ : Amyloid beta peptide; BDNF: Brain derived neurotrophic factor; CCL: C-C motif chemokine ligand; CCR: C-C chemokine receptor; CD: Cluster of differentiation; CHME3: Human microglial clone 3 cell line; CM: Conditioned medium; CNS: Central nervous system; coMTb: Human peripheral blood monocytes infected with Mycobacterium tuberculosis; COX: Cyclooxygenase; CSF1-R: Colonystimulating factor 1 receptor; CXCR: C-X-C chemokine receptor; DAPI: 4,6Diamidino-2-phenylindole dihydrochloride; DHA: Docosahexaenoic acid; DMEM: Dulbecco's modified minimal essential medium; ELISA: Enzyme-linked immunosorbent assay; EMEM: Eagle's minimum essential medium; EPA: Eicosapentenoic acid; ERK: Extracellular signal-regulated kinase; FCS: Fetal calf serum; FITC-conjugated: Fluorescein isothiocyanate conjugated; GFAP: Glial fibrillary acidic protein; GM-CSF: Granulocytemacrophage colony-stimulating factor; H2DCF-DA: 2,7-Dichlorodihydrofluorescein diacetate; HBSS: Hank's balanced salt solution; HCV: Hepatitis virus C; HIV: Human immunodeficiency virus; HLA-DR: Human leukocyte Antigen D Related; 
HMC3: Human microglial clone 3 cell line; hTERT: Human telomerase reverse transcriptase; IBA1: Ionized calcium binding adaptor molecule $1_{\text {; }}$

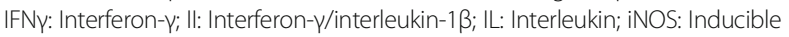
nitric oxide synthase; IP-10: Interferon-y inducible protein 10; IRES: Internal ribosome entry site; IRF: Interferon regulatory factor; JAK: Janus kinases; JEV: Japanese encephalitis virus; LOX: Lipoxygenase; LPS: Lipopolysaccharide; LXA4: Lipoxin A4; Mab: Monoclonal antibody; MAPK: Mitogen-activated protein kinase; MaR: Maresin; MCP-1: Monocyte chemoattractant protein 1; MCSF: Macrophage colony-stimulating factor; M-CSF-R: Macrophage colony-stimulating factor receptor; MFI: Mean fluorescence intensity; MHCII: Class II major histocompatibility complex; miR- or miRNA: MicroRNA; MMF: Monomethylfumarate; MMP: Matrix metalloprotease; NF70KD: Neuronal neurofilament staining; NFKB: Nuclear factor kappa-light-chain-enhancer of activated B cells; NGF : Nerve growth factor; NO: Nitric oxide; NOS2: Inducible nitric oxide synthase; NOX: NADPH oxidase; NPCs: Neuronal precursor cells: NS3: Nonstructural protein 3, also known as p-70; NSE: Nonspecific esterase activity; P2RY12: Purinergic receptor 12; PE-conjugated: Phycoerythrinconjugated; PSA-NCAM: Polysialylated neural cell adhesion molecule; RANTES: Regulated on activation, normal T cell expressed and secreted; ROS: Free oxygen radicals; RvD1: Resolving D1; sAPPa: Secreted amyloid precursor protein-a; $\mathrm{SH}_{\text {swe: }}$ Human neuroblastoma SH-SY5Y cells overexpressing APP 695 Swedish mutation protein; STAT: Signal transducer and activator of transcription; SV40: Simian vacuolating virus 40; TGF: Transforming growth factor; TIMP: Tissue inhibitor of metalloproteinases; TLRs: Toll-like receptors; TMEM119: Transmembrane protein 119; TNFa: Tumor necrosis factor a; TRAF: TNF receptorassociated factor; TREM2: Triggering receptor expressed on myeloid cells 2; TRIM: Tripartite motif-containing protein; TRITC: Tetramethylrhodamine; UTR: Untranslated regions; VEGF: Vascular endothelial growth factor; a7nAcR: a7 nicotinic acetylcholine receptor; aMSH: a-melanocyte stimulating hormone

\section{Acknowledgements}

The authors would like to thank Prof. M. Tardieu, Pediatric Neurology Department Université Paris Sud, Paris, for the clarification of the cell line nomenclature. The authors are grateful to Prof. G. Pani, Institute of General Pathology, Università Cattolica del S. Cuore, Rome, for the stimulating discussion and helpful suggestions on the cell line, and for the critical reading of this manuscript. Finally, the authors would like to acknowledge the support and assistance with flow cytometry received by Dr. Alexia Buzzonetti and Dr. Marco Fossati, Immunology Laboratory, Department of Oncological Gynecology, Università Cattolica del S. Cuore, Rome.

\section{Funding}

The present research is funded by Angelini S.p.A. and by Fondi di Ateneo 2017, Università Cattolica del S. Cuore, both grants awarded to CDR. Data were timely shared with Angelini S.p.A through progress and final reports, and during one internal meeting.

\section{Availability of data and materials}

The datasets used and/or analyzed during the current study are available from the corresponding author on reasonable request.

\section{Authors' contributions}

CDR supervised the experiments, collected and analyzed the data, conceived the paper, and wrote the primary draft. NC handled the HMC3 (ATCC ${ }^{\circledR} \mathrm{CRL}-$ 3304) cell line and performed the experiments and most of the phenotypical and molecular assays. IC supervised the project, contributed to design the experimental plan, and helped with data analysis. DM and FP performed the immunocytochemistry and confocal imaging. GP shared his cell culture protocols and helped in the optimization of culture conditions. PN contributed to study design and manuscript editing. AB performed the flow cytometric analysis. NC and $A B$ significantly contributed to the literature revision and manuscript editing. All authors read and approved the final manuscript.

\section{Ethics approval and consent to participate}

All the experiments were carried out on the human microglial cell line, HMC3 (ATCC ${ }^{\oplus}$ CRL-3304) cells authenticated and distributed by ATCC ${ }^{\oplus}$. The cell line has been used under the term and conditions indicated in the approved material transfer agreement. The use of a single anonymized human genomic DNA sample was authorized by ViiV Healthcare Ldt., under the terms and conditions signed by the Italian HLA-B*57:01 Virological-Clinical Network. Ethics approval was not required since the sample derived from a previous study is approved by the local Ethical Committee which comprised future use for methodological studies [112]

\section{Consent for publication}

We used a single anonymized human genomic DNA sample provided by ViiV Healthcare Ltd., for which consent for publication is not required [112]

\section{Competing interests}

The authors declare that they have no competing interests.

\section{Publisher's Note}

Springer Nature remains neutral with regard to jurisdictional claims in published maps and institutional affiliations.

\section{Author details \\ ${ }^{1}$ Institute of Pharmacology, Università Cattolica del S. Cuore, L.go F Vito 1, 00168 Rome, Italy. ${ }^{2}$ Pharmacology Unit, Fondazione Policlinico Universitario A. Gemelli IRCCS, Rome, Italy. ${ }^{3}$ Angelini RR\&D (Research, Regulatory \& Development) - Angelini S.p.A., Rome, Italy. ${ }^{4}$ Institute of Human Physiology, Università Cattolica del S. Cuore, Rome, Italy. ${ }^{5}$ Institute of Otolaryngology, Università Cattolica del S. Cuore, Rome, Italy. Immunology Laboratory, Department of Oncological Gynecology, Università Cattolica del S. Cuore, Rome, Italy.}

Received: 12 June 2018 Accepted: 21 August 2018

Published online: 10 September 2018

\section{References}

1. Butovsky O, Jedrychowski MP, Moore CS, Cialic R, Lanser AJ, Gabriely G, Koeglsperger T, Dake B, Wu PM, Doykan CE, Fanek Z, Liu L, Chen Z, Rothstein JD, Ransohoff RM, Gygi SP, Antel JP, Weiner HL. Identification of a unique TGF- $\beta$-dependent molecular and functional signature in microglia. Nat Neurosci. 2014;17:131-43.

2. Gosselin D, Skola D, Coufal NG, Holtman IR, Schlachetzki JCM, Sajti E, Jaeger BN, O'Connor C, Fitzpatrick C, Pasillas MP, Pena M, Adair A, Gonda DD, Levy ML, Ransohoff RM, Gage FH, Glass CK. An environment-dependent transcriptional network specifies human microglia identity. Science. 2017;356 https://doi.org/10. 1126/science.aal3222.

3. Sousa C, Biber K, Michelucci A. Cellular and molecular characterization of microglia: a unique immune cell population. Front Immunol. 2017:8:198. https://doi.org/10.3389/fimmu.2017.00198

4. Salter MW, Stevens B. Microglia emerge as central players in brain disease. Nat Med. 2017;23:1018-27.

5. Wake H, Moorhouse AJ, Jinno S, Kohsaka S, Nabekura J. Resting microglia directly monitor the functional state of synapses in vivo and determine the fate of ischemic terminals. J Neurosci. 2009:29:3974-80.

6. Tremblay ME, Lowery RL, Majewska AK. Microglial interactions with synapses are modulated by visual experience. PLoS Biol. 2010;8: e1000527.

7. Paolicelli RC, Bolasco G, Pagani F, Maggi L, Scianni M, Panzanelli P, Giustetto M, Ferreira TA, Guiducci E, Dumas L, Ragozzino D, Gross CT. Synaptic pruning by microglia is necessary for normal brain development. Science. 2011;333:1456-8.

8. Chen Z, Jalabi W, Hu W, Park HJ, Gale JT, Kidd GJ, Bernatowicz R, Gossman ZC, Chen JT, Dutta R, Trapp BD. Microglial displacement of inhibitory synapses provides neuroprotection in the adult brain. Nat Commun. 2014;5:4486.

9. Sierra A, Encinas JM, Deudero JJ, Chancey JH, Enikolopov G, OverstreetWadiche LS, Tsirka SE, Maletic-Savatic M. Microglia shape adult hippocampal neurogenesis through apoptosis-coupled phagocytosis. Cell Stem Cell. 2010; 7:483-95.

10. Ueno M, Fujita Y, Tanaka T, Nakamura Y, Kikuta J, Ishii M, Yamashita T. Layer $\checkmark$ cortical neurons require microglial support for survival during postnatal development. Nat Neurosci. 2013;16:543-51.

11. Shigemoto-Mogami Y, Hoshikawa K, Goldman JE, Sekino Y, Sato K. Microglia enhance neurogenesis and oligodendrogenesis in the early postnatal subventricular zone. J Neurosci. 2014;34:2231-43. 
12. Du L, Zhang Y, Chen Y, Zhu J, Yang Y, Zhang HL. Role of microglia in neurological disorders and their potentials as a therapeutic target. Mol Neurobiol. 2017;54:7567-84.

13. Dello Russo C, Lisi L, Tentori L, Navarra P, Graziani G, Combs CK. Exploiting microglial functions for the treatment of glioblastoma. Curr Cancer Drug Targets. 2017:17:267-81.

14. Lin L, Desai R, Wang X, Lo EH, Xing C. Characteristics of primary rat microglia isolated from mixed cultures using two different methods. J Neuroinflammation. 2017;14:101.

15. Figuera-Losada M, Rojas C, Slusher BS. Inhibition of microglia activation as a phenotypic assay in early drug discovery. J Biomol Screen. 2014;19:17-31.

16. Smith AM, Dragunov M. The human side of microglia. Trends Neurosci. 2014;37:125-35

17. Janabi N, Peudenier S, Héron B, Ng KH, Tardieu M. Establishment of human microglial cell lines after transfection of primary cultures of embryonic microglial cells with the SV40 large T antigen. Neurosci Lett. 1995;195:105-8.

18. Nagai A, Nakagawa E, Hatori K, Choi HB, McLarnon JG, Lee MA, Kim SU. Generation and characterization of immortalized human microglial cell lines: expression of cytokines and chemokines. Neurobiol Dis. 2001;8:1057-68.

19. Garcia-Mesa Y, Jay TR, Checkley MA, Luttge B, Dobrowolski C, Valadkhan S, Landreth GE, Karn J, Alvarez-Carbonell D. Immortalization of primary microglia: a new platform to study HIV regulation in the central nervous system. J Neuro-Oncol. 2017:23:47-66.

20. Li B, Bedard K, Sorce S, Hinz B, Dubois-Dauphin M, Krause KH. NOX4 expression in human microglia leads to constitutive generation of reactive oxygen species and to constitutive IL-6 expression. J Innate Immun. 2009;1:570-81.

21. Jadhav VS, Krause KH, Singh SK. HIV-1 Tat C modulates NOX2 and NOX4 expressions through miR-17 in a human microglial cell line. J Neurochem. 2014;131:803-15.

22. Nakagawa Y, Chiba K. Diversity and plasticity of microglial cells in psychiatric and neurological disorders. Pharmacol Ther. 2015;154:21-35.

23. Reiner A, Heldt SA, Presley CS, Guley NH, Elberger AJ, Deng Y, D'Surney L, Rogers JT, Ferrell J, Bu W, Del Mar N, Honig MG, Gurley SN, Moore BM. Motor, visual and emotional deficits in mice after closed-head mild traumatic brain injury are alleviated by the novel CB2 inverse agonist SMM-189. Int J Mol Sci. 2014;16:758-87.

24. Zhu W, Carney KE, Pigott VM, Falgoust LM, Clark PA, Kuo JS, Sun D. Gliomamediated microglial activation promotes glioma proliferation and migration: roles of $\mathrm{Na}+/ \mathrm{H}+$ exchanger isoform 1. Carcinogenesis. 2016;37:839-51.

25. Patel AB, Tsilioni I, Leeman SE, Theoharides TC. Neurotensin stimulates sortilin and mTOR in human microglia inhibitable by methoxyluteolin, a potential therapeutic target for autism. PNAS. 2016;113:E7049-58.

26. Roy S, Gumulec J, Kumar A, Raudenska M, Baig MH, Polanska H, Balvan J, Gupta M, Babula P, Odstrčilík J, Choi I, Provaznik I, Masarik M. The effect of Benzothiazolone-2 on the expression of Metallothionein-3 in modulating Alzheimer's disease. Brain Behav. 2017;7:e00799.

27. Harris AR, Yuan JX, Munson JM. Assessing multiparametric drug response in tissue engineered tumor microenvironment models. Methods. 2018; 134-135:20-31.

28. Rees GF, Lago SG, Cox DA, Tomasik J, Rustogi N, Weigelt K, Ozcan S, Cooper J, Drexhage $\mathrm{H}$, Leweke FM, Bahn S. Evidence of microglial activation following exposure to serum from first-onset drug-naïve schizophrenia patients. Brain Behav Immun. 2018:67:364-73. https://doi.org/10.1016/j.bbi.2017.10.003.

29. Etemad S, Zamin RM, Ruitenberg MJ, Filgueira L. A novel in vitro human microglia model: characterization of human monocyte-derived microglia. J Neurosci Methods. 2012;209:79-89.

30. Ambrosius B, Faissner S, Guse K, von Lehe M, Grunwald T, Gold R, Grewe B, Chan A. Teriflunomide and monomethylfumarate target HIV-induced neuroinflammation and neurotoxicity. J Neuroinflammation. 2017;14:51.

31. Jašprová J, Dal Ben M, Hurný D, Hwang S, Žižzalová K, Kotek J, Wong RJ, Stevenson DK, Gazzin S, Tiribelli C, Vítek L. Neuro-inflammatory effects of photodegradative products of bilirubin. Sci Rep. 2018;8:7444.

32. Li H, Zhang X, Chen M, Chen J, Gao T, Yao S. Dexmedetomidine inhibits inflammation in microglia cells under stimulation of LPS and ATP by c-Fos/ NLRP3/caspase-1 cascades. EXCLI J. 2018;17:302-11.

33. Peudenier S, Hery C, Montagnier L, Tardieu M. Human microglial cells: characterization in cerebral tissue and in primary culture, and study of their susceptibility to HIV-1 infection. Ann Neurol. 1991;29:152-61.

34. Sébire G, Emilie D, Wallon C, Héry C, Devergne O, Delfraissy JF, Galanaud P, Tardieu M. In vitro production of IL-6, LL-1 beta, and tumor necrosis factor-alpha by human embryonic microglial and neural cells. J Immunol. 1993;150:1517-23.
35. Cross AK, Woodroofe MN. Chemokines induce migration and changes in actin polymerization in adult rat brain microglia and a human fetal microglial cell line in vitro. J Neurosci Res. 1999;55:17-23.

36. Hjorth $\mathrm{E}$, Frenkel $\mathrm{D}$, Weiner $\mathrm{H}$, Schultzberg $\mathrm{M}$. Effects of immunomodulatory substances on phagocytosis of a beta(1-42) by human microglia. Int J Alzheimers Dis. 2010; https://doi.org/10.4061/2010/798424.

37. Liu J, Hjorth E, Zhu M, Calzarossa C, Samuelsson EB, Schultzberg M, Åkesson E. Interplay between human microglia and neural stem/progenitor cells in an allogeneic co-culture model. J Cell Mol Med. 2013;17:1434-43.

38. Flynn G, Maru S, Loughlin J, Romero IA, Male D. Regulation of chemokine receptor expression in human microglia and astrocytes. J Neuroimmunol. 2003;136:84-93.

39. Zhu M, Wang X, Hjorth E, Colas RA, Schroeder L, Granholm AC, Serhan CN, Schultzberg M. Pro-resolving lipid mediators improve neuronal survival and increase Aß42 phagocytosis. Mol Neurobiol. 2016;53:2733-49.

40. Rajalakshmy AR, Malathi J, Madhavan HN. Hepatitis C virus NS3 mediated microglial inflammation via TLR2/TLR6 MyD88/NF-KB pathway and toll like receptor ligand treatment furnished immune tolerance. PLoS One. 2015; 10:e0125419.

41. Nijaguna MB, Patil V, Urbach S, Shwetha SD, Sravani K, Hegde AS, Chandramouli BA, Arivazhagan A, Marin P, Santosh V, Somasundaram K. Glioblastoma-derived macrophage colony-stimulating factor (MCSF) induces microglial release of insulin-like growth factor-binding protein 1 (IGFBP1) to promote angiogenesis. J Biol Chem. 2015;290:23401-15.

42. Ransohoff RM, Schafer D, Vincent A, Blachère NE, Bar-Or A. Neuroinflammation: ways in which the immune system affects the brain. Neurotherapeutics. 2015;12:896-909.

43. Hjorth E, Zhu M, Toro VC, Vedin I, Palmblad J, Cederholm T, Freund-Levi Y, Faxen-Irving G, Wahlund LO, Basun H, Eriksdotter M, Schultzberg M. Omega3 fatty acids enhance phagocytosis of Alzheimer's disease-related amyloid$\beta 42$ by human microglia and decrease inflammatory markers. J Alzheimers Dis. 2013;35:697-713.

44. Zhu M, Wang X, Schultzberg M, Hjorth E. Differential regulation of resolution in inflammation induced by amyloid- $\beta 42$ and lipopolysaccharides in human microglia. J Alzheimers Dis. 2015;43:1237-50.

45. Sedgwick JD, Schwender S, Imrich H, Dörries R, Butcher GW, ter Meulen V. Isolation and direct characterization of resident microglial cells from the normal and inflamed central nervous system. Proc Natl Acad Sci U S A. 1991;88:7438-42.

46. Martin S, Vincent JP, Mazella J. Involvement of the neurotensin receptor-3 in the neurotensin-induced migration of human microglia. J Neurosci. 2003;23: 1198-205.

47. Lindberg C, Hjorth E, Post C, Winblad B, Schultzberg M. Cytokine production by a human microglial cell line: effects of beta-amyloid and alphamelanocyte-stimulating hormone. Neurotox Res. 2005;8:267-76.

48. Lindberg C, Crisby M, Winblad B, Schultzberg M. Effects of statins on microglia. J Neurosci Res. 2005:82:10-9.

49. Baldassarre M, Baronio CM, Morozova-Roche LA, Barth A. Amyloid $\beta$ peptides 1-40 and 1-42 form oligomers with mixed $\beta$-sheets. Chem Sci. 2017;8:8247-54.

50. Fernandes A, Ribeiro AR, Monteiro M, Garcia G, Vaz AR, Brites D. Secretome from SH-SY5Y APP(Swe) cells trigger time-dependent CHME3 microglia activation phenotypes, ultimately leading to miR-21 exosome shuttling. Biochimie. 2018; https://doi.org/10.1016/j.biochi.2018.05.015.

51. Gasic-Milenkovic J, Dukic-Stefanovic S, Deuther-Conrad W, Gärtner U, Münch G. $\beta$-Amyloid peptide potentiates inflammatory responses induced by lipopolysaccharide, interferon $-\gamma$ and 'advanced glycation endproducts' in a murine microglia cell line. Eur J Neurosci. 2003;17:813-21.

52. Shahbazi S, Kaur J, Singh S, Achary KG, Wani S, Jema S, Akhtar J, Sobti RC. Impact of novel $\mathrm{N}$-aryl piperamide NO donors on NF-KB translocation in neuroinflammation: rational drug-designing synthesis and biological evaluation. Innate Immun. 2018;24:24-39.

53. Pareek S, Roy S, Kumari B, Jain P, Banerjee A, Vrati S. MiR-155 induction in microglial cells suppresses Japanese encephalitis virus replication and negatively modulates innate immune responses. J Neuroinflammation. 2014;11:97.

54. Kumari B, Jain P, Das S, Ghosal S, Hazra B, Trivedi AC, Basu A, Chakrabarti J, Vrati $S$, Banerjee A. Dynamic changes in global microRNAome and transcriptome reveal complex miRNA-mRNA regulated host response to Japanese encephalitis virus in microglial cells. Sci Rep. 2016;6:20263.

55. Manocha GD, Mishra R, Sharma N, Kumawat KL, Basu A, Singh SK. Regulatory role of TRIM21 in the type-l interferon pathway in Japanese 
encephalitis virus-infected human microglial cells. J Neuroinflammation. 2014;11:24.

56. Sharma N, Verma R, Kumawat KL, Basu A, Singh SK. miR-146a suppresses cellular immune response during Japanese encephalitis virus JaOArS982 strain infection in human microglial cells. J Neuroinflammation. 2015;12:30.

57. Sharma N, Kumawat KL, Rastogi M, Basu A, Singh SK. Japanese encephalitis virus exploits the microRNA-432 to regulate the expression of suppressor of cytokine signaling (SOCS) 5. Sci Rep. 2016;6:27685.

58. Gupta MK, Behera SK, Dehury B, Mahapatra N. Identification and characterization of differentially expressed genes from human microglial cell samples infected with Japanese encephalitis virus. J Vector Borne Dis. 2017;54:131-8.

59. Rawat $\mathrm{P}$, Spector SA. Development and characterization of a human microglia cell model of HIV-1 infection. J Neuro-Oncol. 2017;23:33-46.

60. Forton DM, Karayiannis P, Mahmud N, Taylor-Robinson SD, Thomas HC. Identification of unique hepatitis $\mathrm{C}$ virus quasispecies in the central nervous system and comparative analysis of internal translational efficiency of brain, liver, and serum variants. J Virol. 2004:78:5170-83.

61. Wang JS, Wu D, Huang DY, Lin WW. TAK1 inhibition-induced RIP1dependent apoptosis in murine macrophages relies on constitutive TNF-a signaling and ROS production. J Biomed Sci. 2015;22:76.

62. Meertens L, Labeau A, Dejarnac O, Cipriani S, Sinigaglia L, Bonnet-Madin L, Le Charpentier T, Hafirassou ML, Zamborlini A, Cao-Lormeau VM, Coulpier M, Missé D, Jouvenet N, Tabibiazar R, Gressens P, Schwartz O, Amara A. Ax mediates Zika virus entry in human glial cells and modulates innate immune responses. Cell Rep. 2017;18:324-33.

63. Mishra R, Chhatbar C, Singh SK. HIV-1 tat C-mediated regulation of tumor necrosis factor receptor-associated factor-3 by microRNA 32 in human microglia. J Neuroinflammation. 2012;9:131.

64. Hughes $C E$, Nibbs RJB. A guide to chemokines and their receptors. FEBS J. 2018; https://doi.org/10.1111/febs.14466.

65. Le Thuc O, Blondeau N, Nahon JL, Rovère C. The complex contribution of chemokines to neuroinflammation: switching from beneficial to detrimental effects. Ann N Y Acad Sci. 2015;1351:127-40.

66. Chou J, Chan MF, Werb Z. Metalloproteinases: a functional pathway for myeloid cells. Microbiol Spectr. 2016;4(2). https://doi.org/10.1128/ microbiolspec.MCHD-0002-2015.

67. Cross AK, Woodroofe MN. Chemokine modulation of matrix metalloproteinase and TIMP production in adult rat brain microglia and a human microglial cell line in vitro. Glia. 1999;28:183-9.

68. Green JA, Rand L, Moores R, Dholakia S, Pezas T, Elkington PT, Friedland JS, In an in vitro model of human tuberculosis, monocyte-microglial networks regulate matrix metalloproteinase-1 and -3 gene expression and secretion via a p38 mitogen activated protein kinase-dependent pathway. J Neuroinflammation. 2013;10:107.

69. Frentzou GA, Bradford C, Harkness KA, Haddock G, Woodroofe MN, Cross AK. IL-1 $\beta$ down-regulates ADAMTS-13 mRNA expression in cells of the central nervous system. J Mol Neurosci. 2012:46:343-51.

70. Nicholson E, Randall AD. Na(v)1.5 sodium channels in a human microglial cell line. J Neuroimmunol. 2009;215:25-30

71. Sessa G, Podini P, Mariani M, Meroni A, Spreafico R, Sinigaglia F, Colonna M, Panina P, Meldolesi J. Distribution and signaling of TREM2/DAP12, the receptor system mutated in human polycystic lipomembraneous osteodysplasia with sclerosing leukoencephalopathy dementia. Eur J Neurosci. 2004;20:2617-28.

72. Macouillard-Poulletier de Gannes F, Merle M, Canioni P, Voisin PJ. Metabolic and cellular characterization of immortalized human microglial cells under heat stress. Neurochem Int. 1998;33:61-73.

73. Voisin P, Bouchaud V, Merle M, Diolez P, Duffy L, Flint K, Franconi JM, BouzierSore AK. Microglia in close vicinity of glioma cells: correlation between phenotype and metabolic alterations. Front Neuroenerg. 2010;2:131.

74. Atanassov CL, Muller CD, Dumont S, Rebel G, Poindron P, Seiler N. Effect of ammonia on endocytosis and cytokine production by immortalized human microglia and astroglia cells. Neurochem Int. 1995;27:417-24.

75. Macouillard-Poulletier de Gannes F, Belaud-Rotureau MA, Voisin P, Leduca N, Belloc F, Canioni P, Diolez P. Flow cytometric analysis of mitochondrial activity in situ: application to acetylceramide-induced mitochondrial swelling and apoptosis. Cytometry. 1998;33:333-9.

76. Shaikh SB, Nicholson LF. Effects of chronic low dose rotenone treatment on human microglial cells. Mol Neurodegener. 2009;4:55.

77. Macouillard-Poulletier de Gannes F, Leducq N, Diolez P, Belloc F, Merle M, Canioni P, Voisin PJ. Mitochondrial impairment and recovery after heat shock treatment in a human microglial cell line. Neurochem Int. 2000;36: 233-41.

78. Shaikh SB, Uy B, Perera A, Nicholson LF. AGEs-RAGE mediated up-regulation of connexin43 in activated human microglial CHME-5 cells. Neurochem Int. 2012;60:640-51.

79. Bigl K, Gaunitz F, Schmitt A, Rothemund S, Schliebs R, Münch G, Arendt T. Cytotoxicity of advanced glycation endproducts in human micro- and astroglial cell lines depends on the degree of protein glycation. J Neural Transm. 2008;115:1545-56.

80. Remondini D, Nylund R, Reivinen J, Poulletier de Gannes F, Veyret B, Lagroye I, Haro E, Trillo MA, Capri M, Franceschi C, Schlatterer K, Gminski R, Fitzner R, Tauber R, Schuderer J, Kuster N, Leszczynski D, Bersani F, Maercker C. Gene expression changes in human cells after exposure to mobile phone microwaves. Proteomics. 2006;6:4745-54.

81. Chen H, Chong ZZ, De Toledo SM, Azzam El, Elkabes S, Souayah N. Delayed activation of human microglial cells by high dose ionizing radiation. Brain Res. 2016;1646:193-8.

82. Chugh P, Fan S, Planelles V, Maggirwar SB, Dewhurst S, Kim B. Infection of human immunodeficiency virus and intracellular viral Tat protein exert a pro-survival effect in a human microglial cell line. J Mol Biol. 2007;366:67-81.

83. Chugh P, Bradel-Tretheway B, Monteiro-Filho CM, Planelles V, Maggirwar SB, Dewhurst S, Kim B. Akt inhibitors as an HIV-1 infected macrophage-specific anti-viral therapy. Retrovirology. 2008;5:11.

84. Lucas A, Kim Y, Rivera-Pabon O, Chae S, Kim DH, Kim B. Targeting the PI3K Akt cell survival pathway to induce cell death of HIV-1 infected macrophages with alkylphospholipid compounds. PLoS One. 2010;5:e13121.

85. Kim Y, Hollenbaugh JA, Kim DH, Kim B. Novel PI3K/Akt inhibitors screened by the cytoprotective function of human immunodeficiency virus type 1 tat. PLoS One. 2011;6:e21781.

86. Aalinkeel R, Mangum CS, Abou-Jaoude E, Reynolds JL, Liu M, Sundquist K, Parikh NU, Chaves LD, Mammen MJ, Schwartz SA, Mahajan SD. Galectin-1 reduces neuroinflammation via modulation of nitric oxide-arginase signaling in HIV-1 transfected microglia: a gold nanoparticle-Galectin-1 "Nanoplex" a possible neurotherapeutic? J Neurolmmune Pharmacol. 2017; 12:133-51.

87. Alvarez-Carbonell D, Garcia-Mesa Y, Milne S, Das B, Dobrowolski C, Rojas R, Karn J. Toll-like receptor 3 activation selectively reverses HIV latency in microglial cells. Retrovirology. 2017;14:9.

88. Xiao R, Li S, Cao Q, Wang X, Yan Q, Tu X, Zhu Y, Zhu F. Human endogenous retrovirus $W$ env increases nitric oxide production and enhances the migration ability of microglia by regulating the expression of inducible nitric oxide synthase. Virol Sin. 2017:32:216-25.

89. Campbell LA, Richie CT, Zhang Y, Heathward EJ, Coke LM, Park EY, Harvey BK. In vitro modeling of HIV proviral activity in microglia. FEBS J. 2017;284: 4096-114.

90. Samikkannu T, Atluri VS, Nair MP. HIV and cocaine impact glial metabolism: energy sensor AMP-activated protein kinase role in mitochondrial biogenesis and epigenetic remodeling. Sci Rep. 2016;6:31784.

91. Zhang Y, Yin C, Zhang T, Li F, Yang W, Kaminski R, Fagan PR, Putatunda R, Young WB, Khalili K, Hu W. CRISPR/gRNA-directed synergistic activation mediator (SAM) induces specific, persistent and robust reactivation of the HIV-1 latent reservoirs. Sci Rep. 2015;5:16277.

92. Jeong JJ, Kim DH. 5,7-Dihydroxy-6-Methoxy-flavonoids eliminate HIV-1 D3transfected cytoprotective macrophages by inhibiting the PI3K/Akt signaling pathway. Phytother Res. 2015;29:1355-65.

93. Zenón F, Cantres-Rosario Y, Adiga R, Gonzalez M, Rodriguez-Franco E, Langford D, Melendez LM. HIV-infected microglia mediate cathepsin Binduced neurotoxicity. J Neuro-Oncol. 2015;21:544-58.

94. Jeong JJ, Kim B, Kim DH. Ginsenoside Rb1 eliminates HIV-1 (D3)-transduced cytoprotective human macrophages by inhibiting the AKT pathway. J Med Food. 2014;17:849-54.

95. Yoo SY, Le TK, Jeong JJ, Kim DH. Poligapolide, a PI3K/Akt inhibitor in immunodeficiency virus type 1 TAT-transduced CHME5 cells, isolated from the rhizome of Polygala tenuifolia. Chem Pharm Bull. 2014;62:467-71.

96. Jeong JJ, Kim B, Kim DH. Ginsenoside Rh1 eliminates the cytoprotective phenotype of human immunodeficiency virus type 1-transduced human macrophages by inhibiting the phosphorylation of pyruvate dehydrogenase lipoamide kinase isozyme 1. Biol Pharm Bull. 2013;36:1088-94.

97. Le TK, Jeong JJ, Kim DH. Clionosterol and ethyl cholestan-22-enol isolated from the rhizome of Polygala tenuifolia inhibit phosphatidylinositol 3kinase/Akt pathway. Biol Pharm Bull. 2012;35:1379-83. 
98. Wires ES, Alvarez D, Dobrowolski C, Wang Y, Morales M, Karn J, Harvey BK. Methamphetamine activates nuclear factor kappa-light-chain-enhancer of activated B cells (NF-KB) and induces human immunodeficiency virus (HIV) transcription in human microglial cells. J Neuro-Oncol. 2012:18:400-10.

99. Cox C, Cao S, Lu Y. Enhanced detection and study of murine norovirus-1 using a more efficient microglial cell line. Virol J. 2009;6:196. https://doi.org/ 10.1186/1743-422X-6-196.

100. Dreses-Werringloer U, Bhuiyan M, Zhao Y, Gérard HC, Whittum-Hudson JA, Hudson AP. Initial characterization of Chlamydophila (chlamydia) pneumoniae cultured from the late-onset Alzheimer brain. Int J Med Microbiol. 2009;299:187-201.

101. Abere B, Wikan N, Ubol S, Auewarakul P, Paemanee A, Kittisenachai S, Roytrakul S, Smith DR. Proteomic analysis of chikungunya virus infected microgial cells. PLoS One. 2012;7:e34800. https://doi.org/10.1371/journal. pone. 0034800

102. Arbour N, Côté G, Lachance C, Tardieu M, Cashman NR, Talbot PJ. Acute and persistent infection of human neural cell lines by human coronavirus OC43. J Virol. 1999;73:3338-50.

103. Arbour N, Ekandé S, Côté G, Lachance C, Chagnon F, Tardieu M, Cashman NR, Talbot PJ. Persistent infection of human oligodendrocytic and neuroglial cell lines by human coronavirus 229E. J Virol. 1999;73:3326-37.

104. Wolf B, Diop F, Ferraris P, Wichit S, Busso C, Missé D, Gönczy P. Zika virus causes supernumerary foci with centriolar proteins and impaired spindle positioning. Open Biol. 2017;7 https://doi.org/10.1098/rsob.160231.

105. Edwards JA, Denis F, Talbot PJ. Activation of glial cells by human coronavirus OC43 infection. J Neuroimmunol. 2000;108:73-81.

106. Lisi L, Laudati E, Miscioscia TF, Dello Russo C, Topai A, Navarra P. Antiretrovirals inhibit arginase in human microglia. J Neurochem. 2016;136: 363-72.

107. Kaur G, Dufour JM. Cell lines: valuable tools or useless artifacts. Spermatogenesis. 2012;2:1-5.

108. Corral-Vázquez C, Aguilar-Quesada R, Catalina P, Lucena-Aguilar G, Ligero G, Miranda B, Carrillo-Ávila JA. Cell lines authentication and mycoplasma detection as minimun quality control of cell lines in biobanking. Cell Tissue Bank. 2017;18:271-80.

109. Dello Russo C, Lisi L, Tringali G, Navarra P. Involvement of mTOR kinase in cytokine-dependent microglial activation and cell proliferation. Biochem Pharmacol. 2009;78:1242-51.

110. Dello Russo C, Lisi L, Lofaro A, Di Giambenedetto S, Federico B, Madeddu G, Salerno M, Mura MS, Pirazzoli A, de Luca A, Cauda R, Navarra P. Novel sensitive, specific and rapid pharmacogenomic test for the prediction of abacavir hypersensitivity reaction: HLA-B*57:01 detection by real-time PCR. Pharmacogenomics. 2011;12(4):567-76.

111. Cereb N, Maye P, Lee S, Kong Y, Yang SY. Locus-specific amplification of HLA class I genes from genomic DNA: locus-specific sequences in the first and third introns of HLA-A, -B, and - C alleles. Tissue Antigens. 1995;45(1):111.

112. Meini G, Dello Russo C, Allice T, Barresi R, D'Arrigo R, Falasca F, Lipsi MR, Paolucci S, Zanussi S, Antonetti R, Baldanti F, Basaglia G, Bruzzone B, Polilli E, Ghisetti V, Pucillo LP, Turriziani O, Pirazzoli A, Navarra P, Zazzi M. First external quality assurance program of the Italian HLA-B*57:01 network assessing the performance of clinical virology laboratories in HLA-B*57:01 testing. J Clin Virol. 2016;78:1-3.

113. Lisi L, Tramutola A, Navarra P, Dello Russo C. Antiretroviral agents increase NO production in gp120/IFNy-stimulated cultures of rat microglia via an arginase-dependent mechanism. J Neuroimmunol. 2014;266:24-32.

\section{Ready to submit your research? Choose BMC and benefit from}

- fast, convenient online submission

- thorough peer review by experienced researchers in your field

- rapid publication on acceptance

- support for research data, including large and complex data types

- gold Open Access which fosters wider collaboration and increased citations

- maximum visibility for your research: over $100 \mathrm{M}$ website views per year

At BMC, research is always in progress.

Learn more biomedcentral.com/submissions 